\title{
Drivers and potential predictability of summer time North Atlantic polar front jet variability
}

\author{
Richard J. Hall ${ }^{1} \cdot$ Julie M. Jones $^{1} \cdot$ Edward Hanna $^{1} \cdot$ Adam A. Scaife $^{2} \cdot$ \\ Róbert Erdélyi ${ }^{3,4}$
}

Received: 28 October 2015 / Accepted: 30 June 2016 / Published online: 24 August 2016

(C) The Author(s) 2016. This article is published with open access at Springerlink.com

\begin{abstract}
The variability of the North Atlantic polar front jet stream is crucial in determining summer weather around the North Atlantic basin. Recent extreme summers in western Europe and North America have highlighted the need for greater understanding of this variability, in order to aid seasonal forecasting and mitigate societal, environmental and economic impacts. Here we find that simple linear regression and composite models based on a few predictable factors are able to explain up to $35 \%$ of summertime jet stream speed and latitude variability from 1955 onwards. Sea surface temperature forcings impact predominantly on jet speed, whereas solar and cryospheric forcings appear to influence jet latitude. The cryospheric associations come from the previous autumn, suggesting the survival of an ice-induced signal through the winter season, whereas solar influences lead jet variability by a few years. Regression models covering the earlier part of the twentieth century are much less effective, presumably due to decreased availability of data, and increased uncertainty in observational
\end{abstract}

Richard J. Hall

rjhall1@ sheffield.ac.uk

$\triangle$ Adam A. Scaife

adam.scaife@metoffice.gov.uk

1 Department of Geography, University of Sheffield, Winter Street, Sheffield S10 2TN, UK

2 Met Office Hadley Centre, Exeter, UK

3 Solar Physics and Space Plasma Research Centre, School of Mathematics and Statistics, University of Sheffield, Sheffield, UK

4 Debrecen Heliophysical Observatory (DHO), Research Centre for Astronomy and Earth Sciences, Hungarian Academy of Sciences (HAS), P.O.Box 30, Debrecen 4010, Hungary reanalyses. Wavelet coherence analysis identifies that associations fluctuate over the study period but it is not clear whether this is just internal variability or genuine non-stationarity. Finally we identify areas for future research.

Keywords Polar front jet · Predictors · North Atlantic · Predictability

\section{Introduction}

The North Atlantic is distinctive in the northern hemisphere as it has separate polar front and subtropical jets, particularly in winter. In summer, the jets are weaker than in winter, and displaced northwards. Figure 1 shows the mean position of the summer (JJA) North Atlantic jets at $200-300 \mathrm{hPa}$. The polar front jet (PFJ) is particularly important in influencing the weather and climate of western Europe and North America, and has been implicated in recent instances of extreme weather. For example, summer 2007 was very wet, with record rainfall and flooding and with a distinctive jet formation over the UK (Blackburn et al. 2008). Summer 2012 was characterised by a southward displacement of the PFJ, with high temperatures and severe drought in the central and eastern USA (Hoerling et al. 2013) and record melting and ice mass loss of the Greenland Ice Sheet (Hanna et al. 2014), while the United Kingdom experienced its wettest summer for a century (Dong et al. 2013a) and Spain experienced low rainfall and drought (Dong et al. 2013a). In contrast, Summer 2003 was exceptionally warm and dry in western and central Europe, even though the jet was again south of the mean position, but this time blocked by persistent anticyclonic conditions over Europe (Black et al. 2004). Heatwave conditions caused increased mortality in central Europe (Kosatsky 
2005). Consequently, an understanding of the patterns and causes of such variability in the jet stream, together with its potential predictability, is crucial for mitigating the societal, economic and ecological impacts of such extremes.

There has been an increase in the observed frequency of summer extremes of temperature and precipitation attributed to global warming (Coumou and Rahmstorf 2012). Recent boreal summers have also been characterized by a changing Arctic atmospheric circulation, with increased anticyclonic flow over the Arctic (Ogi and Wallace 2012) and a more persistent negative Arctic Dipole (Overland et al. 2012) associated with increased Greenland blocking (Hanna et al. 2014, 2015) and a strengthened Beaufort Sea high pressure region (Moore 2012; Wu et al. 2014; Ballinger et al. 2014). These have resulted in a southward displacement of the PFJ, leading to cooler wetter summers in Europe, while other areas such as North America have experienced heatwaves and droughts. Zhang et al. (2008) report a similar shift to a dipole type Arctic atmospheric circulation in winter as well as summer, which has the potential to impact on the subsequent summer ice extent, with warmer winters leading to thinner ice which is more susceptible to summer melt. The increased frequency and persistence of extreme events have been linked to a weakening of the zonal-mean jet stream and a more wavy flow pattern, through a decrease in the poleward temperature gradient as a consequence of Arctic amplification (Francis and Vavrus 2012, 2015), although others argue that such linkages are sensitive to methodologies used (Barnes 2013; Screen and Simmonds 2013). A further possible mechanism that has been suggested as leading to extreme and persistent weather patterns is the amplification of quasistationary waves through resonance between forced and free waves in mid-latitude waveguides (Petoukhov et al. 2013; Coumou et al. 2014), which could also have an origin in recent changes in the Arctic. However, while identifying possible trends and changes in frequency of events, such studies have not addressed questions of interannual variability, and the potential predictability of summertime jet stream configurations, which is currently low in long-range forecast systems (e.g. MacLachlan et al. 2014). Here we focus on these issues for the North Atlantic sector, shown in Fig. 1.

The North Atlantic Oscillation (NAO) is the primary mode of atmospheric variability in the North Atlantic (e.g. Hurrell 1995; Hurrell et al. 2003), and it is the main influence on western European weather (Hanna et al. 2015). The NAO is an indicator of jet-stream variability and the North Atlantic storm tracks (e.g. Vallis and Gerber 2008; Woollings et al. 2010), with both the latitude and speed of the jet contributing to the value of the NAO index (Woollings et al. 2010). However, the speed and latitude of the jet are not well correlated in any season $(r=-0.1$ for summer, 1956-2012, detrended time series), suggesting that different factors may influence their variability.

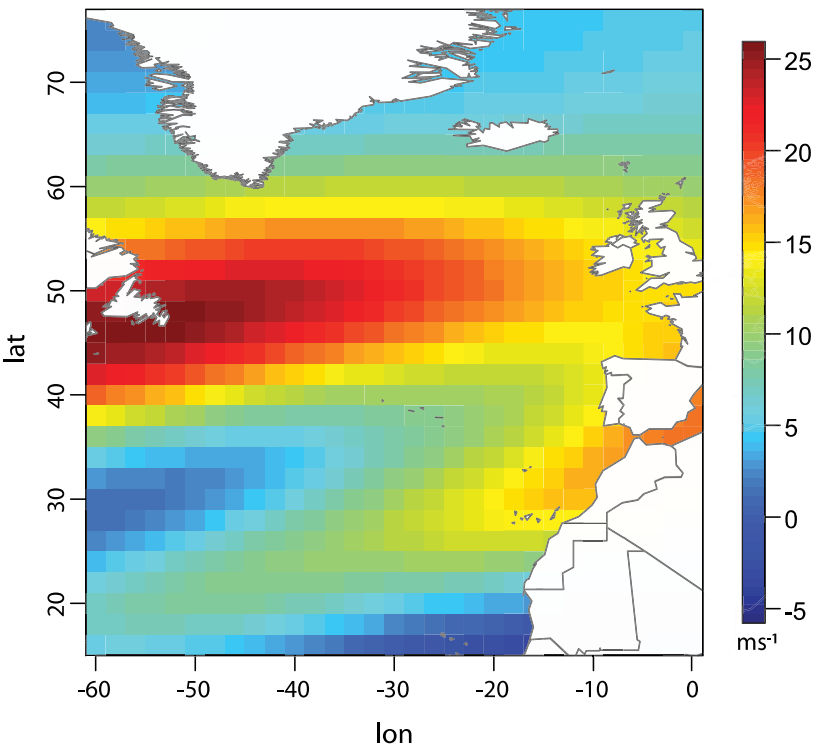

Fig. 1 The region of the North Atlantic used to identify the polar front jet stream, with mean JJA zonal wind speed values for the jet stream, 1981-2010, averaged over 300-200 hPa from ERA-Interim (Dee et al. 2011)

Most work on jet stream variability has focused on the winter season, when the NAO pattern tends to be strongest and most variable (e.g. Woollings et al. 2010; Woollings and Blackburn 2012; Strong and Magnusdottir 2011). The mean summer Atlantic atmospheric circulation is characterized by a weaker, poleward shifted jet (Woollings 2010), and an NAO pattern that shows weaker nodes, shifted in location and identified as the summer NAO (SNAO; e.g. Folland et al. 2009). A positive SNAO, with a further northward displacement of a jet that is already shifted north in summer, is associated with warm sunny weather and anticyclonic conditions in northwest Europe and cooler cloudier conditions in the Mediterranean (Bladé et al. 2012). A negative SNAO is the converse of this (Folland et al. 2009).

There are a number of suggested influences on the jet stream and SNAO (e.g. Hall et al. 2015). The Atlantic Multidecadal Oscillation (AMO; Enfield et al. 2001) is a mode of North Atlantic sea surface temperature (SST) variability with a period of $65-80$ years. It can influence the PFJ and SNAO, with the negative (cold) phase of the AMO being associated with cooler drier summers in western Europe, a northward shift of the PFJ and a positive SNAO on decadal timescales, while the positive phase is associated with warmer wetter summers, with a PFJ displaced southwards from the seasonal climatology and a negative SNAO (Knight et al. 2006; Folland et al. 2009; Sutton and Dong 2012).

The Atlantic Ocean also shows SST fluctuations on shorter interannual and decadal timescales than the AMO, for instance exhibiting a tripolar pattern of SST 
anomalies in the North Atlantic (e.g. Cayan 1992; Czaja and Frankignoul 1999). These anomalies are largely considered to be driven by atmospheric variability (e.g. Deser and Timlin 1997) but have been shown to exert a small but significant contrary influence when SST leads atmospheric variability by up to 6 months, especially in winter (e.g. Deser et al. 2003). Increased westerlies in a positive NAO phase lead to increased poleward SST gradients, with increased temperature differences between tripole nodes. This impacts on sensible and latent heat fluxes at the ocean surface, with increased heat loss to the atmosphere where winds are stronger and heat gains at lower latitudes where winds are weaker (Deser et al. 2010). Vertical mixing processes in the near-surface ocean layers also influence the heat flux (Fan and Schneider 2012; Cayan 1992).

A number of studies indicate a possible sea-ice influence on winter mid-latitude atmospheric variability, with associations between negative sea-ice anomalies and cold Eurasian winters and a more negative NAO (e.g. Wu and Zhang 2010; Strong and Magnusdottir 2011; Kim et al. 2014). However, evidence for a link with summer North Atlantic atmospheric variability is much sparser. Screen (2013) has identified a potential link between sea-ice extent and summer rainfall in western Europe, identifying recent sea-ice losses in the Sea of Okhotsk as a key change for excitation of planetary waves, which may have a subsequent downstream impact on the Atlantic sector. An earlier modelling study also found a robust link between spring sea-ice anomalies over the Sea of Okhotsk and anomalous wavetrain propagation which was able to impact on European summers (Zhao et al. 2004). Wu et al. (2013) reported a correlation between sea-ice anomalies to the west of Greenland in winter and late spring, and summer Eurasian precipitation anomalies. Liu et al. (2016) find a synchronous relationship between summer Arctic sea-ice extent and the incidence of Greenland blocking. Recent research has suggested that Arctic amplification and shrinking snow cover may influence the amplitude of planetary wave patterns (Francis and Vavrus 2012, 2015), although this is controversial (e.g. Barnes 2013; Screen and Simmonds 2013). However, there is also evidence to link earlier Eurasian snowmelt with increased high pressure over the Arctic in summer and a negative annular mode (Matsumura et al. 2014).

Stratosphere-troposphere coupling exerts a potential influence in winter on the PFJ through a range of factors (Kidston et al. 2015; Hall et al. 2015). However, in the summer hemisphere the stratospheric polar vortex breaks down, and easterly flow prevails, which prevents propagation of Rossby waves and so this coupling does not occur and therefore predictors of variability such as the quasi-biennial oscillation (QBO) and the impact of tropical volcanic eruptions, to name but two, are unable to exert a summer-time influence via the stratospheric pathway. The El-NiñoSouthern Oscillation (ENSO) phenomenon is a further factor which is capable of influencing winter North Atlantic atmospheric variability via a stratospheric teleconnection (e.g. Bell et al. 2009), but in addition is able to exert an influence via the troposphere (e.g. Butler et al. 2014) which may not be restricted to winter. Fluctuations in solar output are also identified as impacting upon tropospheric variability, both via the stratosphere and through an influence on SST (e.g. Dong et al. 2013a; Scaife et al. 2013).

Planetary waves can propagate circumglobally following excitation for example by a low-latitude heat source (e.g. Hoskins and Karoly 1981). It has been suggested that the wet summer of 2007 could be linked with stationary wave propagation originating in the Philippines (Blackburn et al. 2008), and Ding and Wang (2005) identify global teleconnection patterns in summer resulting from variability in tropical heating. However, the propagation of waves from the tropics to extratropics is more limited in this season than winter due to changes in the background flow.

This paper presents an exploratory analysis of these potential predictors of summer PFJ variability, through use of statistical analyses. We use linear regression to investigate aspects of relationships between predictors and jet variability, and composite analysis to identify both linear and non-linear components. Lead times of the predictors over the response have potential for developing the predictability of summer jet stream variability. Wavelet coherence provides supporting evidence of the relationship between potential predictors and jet stream variability, together with information on how associations may vary over time. The paper is organised as follows. Sect. 2 describes the datasets used in the analysis and Sect. 3 explains the three main methods of analysis: linear regression, composite analysis and wavelet coherence analysis. Sect. 4 presents the results for each predictor identified as being significant in the analyses and the results are discussed in Sect. 5, with conclusions and areas for future research outlined in Sect. 6.

\section{Data}

Here we use a standardised Nino 3.4 Index, based on SST data from HadISST1 (Rayner et al. 2003), for the period 1871-2012, obtained from www.climexp.knmi.nl.

Two metrics of Atlantic sea surface temperature (SST) are used. Atlantic AMO data (Enfield et al. 2001) were obtained from the Earth System Research Laboratory (www.esrl.noaa.gov/psd/data/timeseries/AMO), for the period 1871-2012, based on the Kaplan SST dataset (Kaplan et al. 1998, updated). A North Atlantic SST tripole index is developed using the methodology of Czaja and Marshall (2001) based on the SST anomaly taken over 


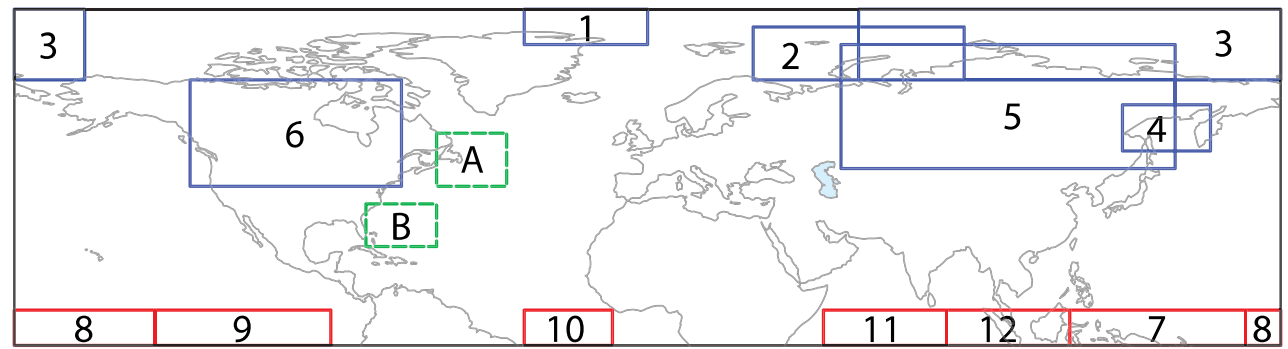

Fig. 2 Map showing areas used for predictor datasets: 1 Greenland Sea, GI; 2 Barents-Kara Seas, BKI; 3 Laptev, East Siberian and Chuckchi seas (LVI); 4 Sea of Okhotsk (OSI); 5 Eurasian snow anomalies; 6 North American snow anomalies; 7 West Pacific

$40^{\circ}-55^{\circ} \mathrm{N}, 60^{\circ}-40^{\circ} \mathrm{W}$ minus the anomaly over a southern box, $25^{\circ}-35^{\circ} \mathrm{N}, 80^{\circ}-60^{\circ} \mathrm{W}$ (Fig. 2). Anomalies are relative to 1981-2010 climatology. This dipole lies to either side of the Gulf Stream, and the southern node of the classic tripole mirrors the northern node identified here. Here a positive index value indicates higher anomalies in the northern sector compared to those in the southern sector, and reflects a reduced meridional temperature gradient.

In the tropics, altered convective activity and divergence aloft in the presence of a vorticity gradient can generate Rossby waves which propagate away from the tropics and are capable of influencing the jet streams (Hoskins and Karoly 1981). Here we use the Global Precipitation Climatology Project v2, which provides global precipitation data at $2.5^{\circ}$ resolution, based on satellite data, 1979-2012, at monthly resolution (Adler et al. 2003). Six sub-sections are taken from the tropics (Fig. 2): three from the Pacific Ocean (West Pacific rainfall (WPR) $5^{\circ} \mathrm{S}-5^{\circ} \mathrm{N}, 120^{\circ}-170^{\circ} \mathrm{E}$; Central Pacific rainfall (CPR) $5^{\circ} \mathrm{S}-5^{\circ} \mathrm{N}, 170 \mathrm{E}-220^{\circ} \mathrm{E}$; East Pacific rainfall (EPR) $5^{\circ} \mathrm{S}-5^{\circ} \mathrm{N}, 220 \mathrm{E}-270^{\circ} \mathrm{E}$ ), two from the Indian Ocean (West Indian Ocean rainfall (WIR) $5^{\circ} \mathrm{S}-$ $5^{\circ} \mathrm{N}, 50^{\circ}-85^{\circ} \mathrm{E}$, East Indian Ocean rainfall (EIR) $5^{\circ} \mathrm{S}-5^{\circ} \mathrm{N}$, $85^{\circ}-120^{\circ} \mathrm{E}$ ) and one from the Atlantic Ocean (AR), $5^{\circ} \mathrm{S}-$ $5^{\circ} \mathrm{N}, 10^{\circ}-35^{\circ} \mathrm{W}$.

Solar-cycle data are available in a variety of forms. In order to obtain data for the whole period, monthly sunspot numbers are obtained from the Solar Influences Data Analysis Center (http://sidc.oma.be/). Analysis is also carried out using solar indices leading by one to 5 years, as recent evidence suggests that there is a lagged North Atlantic climate response to solar variability (Scaife et al. 2013; Gray et al. 2013; Thiéblemont et al. 2015; Andrews et al. 2015).

Sea-ice concentration data are taken from the HadISST1 dataset (Rayner et al. 2003). Only data post-1955 are used, to avoid periods lacking observations, although it is the post-1979 data from the satellite era that are most reliable. This allows for comparisons of the whole time series from 1955 with that of the satellite era. Data are acquired for the whole of the Northern Hemisphere poleward of $40^{\circ} \mathrm{N}$,
Rainfall(WPR); 8 Central Pacific Rainfall (CPR); 9 East Pacific Rainfall (EPR); 10 Atlantic Rainfall (AR); 11 West Indian Ocean rainfall (WIR); 12 East Indian Ocean Rainfall (EIR). $A$ and $B$ show the northern and southern regions used for calculation of the SST tripole index

plus sub-regions identified as being potentially more significant, obtained using correlation maps of sea-ice extent with jet-stream metrics for the periods 1955-2012 and 1979-2012, depending on the availability of potential predictors (not shown). We aim to establish whether total Arctic sea-ice is a significant predictor of jet stream variability, or whether regional sea-ice variability is more significant. Areas identified are the Barents-Kara Sea (BKI; $30^{\circ}-90^{\circ} \mathrm{E}$, $70^{\circ}-85^{\circ} \mathrm{N}$ ), NE Greenland (GI: $35^{\circ}-0^{\circ} \mathrm{W}, 80^{\circ}-90^{\circ} \mathrm{N}$ ) and the area centred on the Laptev Sea (LVI; $60^{\circ}-200^{\circ} \mathrm{E}, 70^{\circ}$ $90^{\circ} \mathrm{N}$ ), but including the East Siberian, Kara and Chukchi Seas (Fig. 2). The Sea of Okhotsk is also included, (OSI; $135^{\circ}-160^{\circ} \mathrm{E}, 50^{\circ}-63^{\circ} \mathrm{N}$ ) to compare with the findings of Screen (2013), although the time series from this latter region is taken from 1979 only, as prior to this fluctuations are subject to poor observational sampling.

Snow cover data for Eurasia $\left(55^{\circ}-150^{\circ} \mathrm{E}, 45^{\circ}-80^{\circ} \mathrm{N}\right.$, ) and North America $\left(130^{\circ}-70^{\circ} \mathrm{W}, 40^{\circ}-70^{\circ} \mathrm{N}\right.$, Fig. 2) are obtained from Rutgers University (Robinson et al. 2012; http://climate.rutgers.edu/snowcover/). Data are used from 1979 to match with other predictors.

All predictors are standardised by subtracting the mean and dividing by the standard deviation for the period 19812010, and data are detrended to focus on covariability of datasets on interannual to multidecadal timescales. Jet speed and latitude are also detrended but not standardised so that the magnitude of any change in the jet metric can be more readily identified.

Zonal wind speeds from the Twentieth Century Reanalysis (20CR) data (Compo et al. 2011) are used to calculate jet latitude and speed, for the area $16^{\circ}-76^{\circ} \mathrm{N}, 0^{\circ}-60^{\circ} \mathrm{W}$ (see Fig. 1). The jet metrics were calculated according to Woollings et al. (2010) and filtered using a 10-day Lanczos lowpass filter with a 61-day window (Duchon 1979), to remove synoptic scale variability. Zonal winds from 900 to $700 \mathrm{hPa}$ are used, as this avoids false detection of the subtropical jet which is found near the tropopause. In 20CR lower altitude pressure levels are likely to have more accurate wind speed representation than levels near the tropopause, where the 
core of the PFJ is found, as the reanalysis assimilates surface pressure measurements only. Numerous studies have utilised this method of jet identification (e.g. Davini et al. 2014; Anstey et al. 2013; Barnes and Polvani 2015), but with a focus predominantly on winter. The latitude of the PFJ is consistent irrespective of the pressure levels sampled (e.g. Woollings et al. 2010). Thus lower-level winds are capable of portraying the interannual variability of the jet core, situated higher in the tropopause.

20CR is based on a 56-member ensemble, but here we use the ensemble mean data. This dataset provides a long time series (here 1872-2012) over which the covariability of potential predictors and jet metrics can be assessed. A further advantage of the $20 \mathrm{CR}$ data is that an ensemble approach provides a measure of the relative changes in the uncertainty of the data, available as the spread (standard deviation) between the 56 ensemble members (Compo et al. 2011). A comparison with data from the ERA-Interim reanalysis (Dee et al. 2011) for the period 1979-2012 shows excellent agreement between the two reanalyses in their representation of jet metrics (not shown). However, there are concerns over the suitability of the earlier part of the dataset for identifying long term trends and variability, where inhomogeneities may arise through increasing observation density and quality over time (e.g. Krueger et al. 2013; Ferguson and Villarini 2014). Inhomogeneities in jet stream time series are identified which could be a consequence of such changes in data quality. These are identified by comparing breakpoints in the time series and in the time series of 20CR spread data by using the Bai-Perron test (Bai and Perron 2003). The coincidence of breakpoints in each series is taken as suggesting the breakpoint originated in data quality issues, and an adjustment is made accordingly (see Ferguson and Villarini 2014 for more details). A comparison with unadjusted data showed that there is little difference in correlation values between predictors and the adjusted and unadjusted time series (not shown). This only impacts upon the time series starting in 1872 (see below), as all adjustments for inhomogeneity are made before 1955. We find that there is very close agreement between jet-stream metric time series post-1950 for the different ensemble members, with interannual variations being in-phase and of similar magnitude. Prior to 1950, there is increased spread although fluctuations in the time series are predominantly in-phase (Fig. 3).

Three periods are used: 1871-2012, 1955-2012,19792012. These are selected to correspond to the availability of potential predictors, so regression models for a given time period consider all available predictors for that period. Due to the use of lagged datasets, the first year of the time series is lost. Consequently the time series start from 1872 , 1956 and 1980 (from hereon the 1872, 1956 and 1980 time series). This also ensures that the earlier part of the
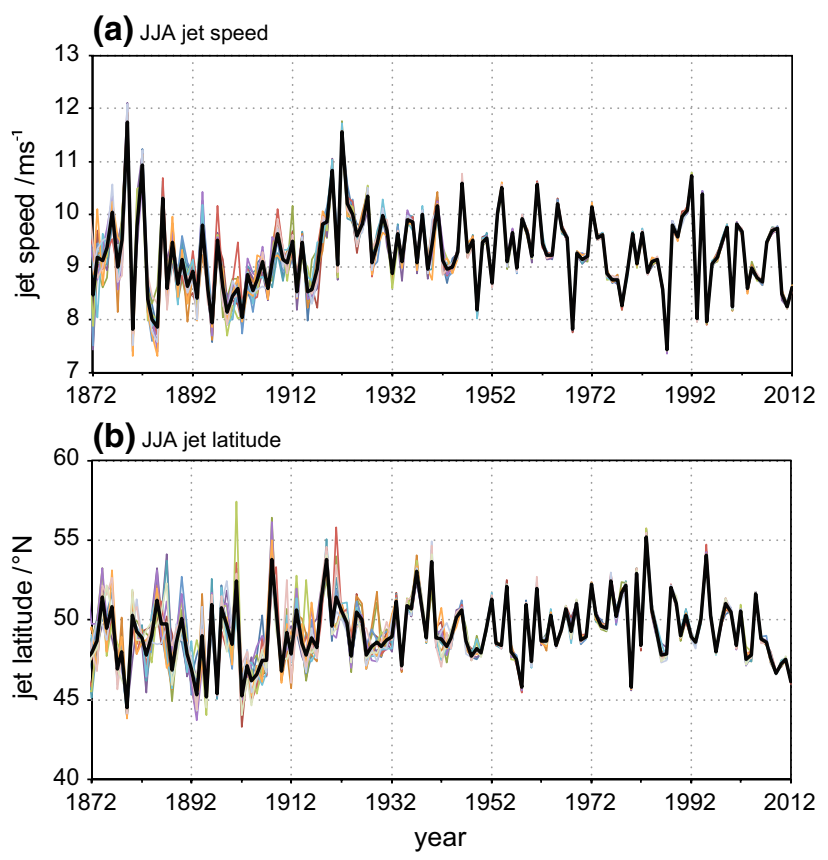

Fig. 3 Jet metric time series for a summer jet speed $\mathbf{b}$ summer jet latitude, showing the separate time series from 15 randomly selected ensemble members (faint coloured lines) and the ensemble mean (black bold line). Data are for the $850 \mathrm{hPa}$ level only. Note that time series are not adjusted for homogeneity

20CR dataset is isolated in the regression analysis, and can be compared with regression models for more recent periods. Sea level pressure (SLP) data are also used from 20CR, to support the composite analysis, through maps of SLP composites for high and low years of a predictor. SLP is preferred to the more usual $500 \mathrm{hPa}$ geopotential height field (500GPH). This is because 20CR is a reanalysis produced by assimilating surface measurements only and there will be increased confidence in the reliability of the SLP field compared with one from the middle troposphere. A comparison of 500GPH and SLP composites (not shown) reveals similar features, validating the use of the SLP field, which allows the identification of barotropic circulation features.

\section{Methods}

\subsection{Regression analysis}

Predictor identification is carried out using multiple linear ordinary least squares regression, following selection of a preliminary pool of predictors identified from observation and modelling studies outlined in Sects. 1 and 2. Correlation matrices are calculated between jet variables and potential predictors (not shown), with jet 
variables lagging the predictors by up to 11 months. Synchronous predictors are only permitted where timescales are physically reasonable and where direction of forcing is clear. For example synchronous tropical precipitation is a potential predictor as the timescale for Rossby wave propagation from the tropics is $7-10$ days. (Hoskins and Karoly 1981). The correlations are used as a guide to indicate which predictors may be associated with jetstream variability. Predictors for models are chosen by forward selection (e.g. Wilks 2011, pp. 247-248). A stopping criterion is selected to avoid overfitting, such that further forward selection will not take place once no further predictors could be added at $p<0.1$ (for the $t$ value of the ratio of the coefficient estimate to the coefficient standard error).

Screening of predictors ensures that multicollinearity between variables is reduced. Predictors showing significant $(95 \%)$ correlation with a prior selected predictor are omitted from subsequent stages of the forward selection.

The Durbin-Watson statistic is calculated for the regression models to test for autocorrelation of residuals (e.g. Wilks 2011, p. 228) and residual plots are examined to check for indications of heteroscedasticity.

In linear regression, the coefficient of determination $\left(\mathrm{R}^{2}\right)$ gives the proportion of the variance of the predictand that can be accounted for by the regression. $\mathrm{R}^{2}$ values can be inflated through the use of too many predictors, known as overfitting, and this can be reduced through cross-validation (e.g. Efron and Gong 1983; Efron and Tibshirani 1993, pp. 237-240). Leave-one out cross-validation (LOOCV) is performed, where each year's value is left out of the model regression in turn, and for $n$ years, the fitting procedure is performed $n$ times with a sample size of $n-1$, each time obtaining a predicted value for the missing year. Revised $\mathrm{R}^{2}$ values based on cross-validation are calculated (denoted $\mathrm{xvR}^{2}$ ). When employing cross-validation, it is important that the year being omitted and predicted has in no way been "seen" previously in the model building process. To this end it is necessary to cross-validate any standardisation of data values, by leaving out the year in question from the climatological period before calculating means and standard deviations of the reference period. This procedure is followed here. Furthermore, the time series of predictors are divided into five groups, or folds, which provides sufficient data values in each group, while allowing subdivision of the data, and the initial correlation coefficient is calculated. A predictor is selected for potential inclusion in the model if a significant correlation occurs between it and the jet variable in more than three of these folds. Thus selection does not take place on the basis of all years. Cross-validation is applied at each stage of the regression model building, to confirm the identification of the selected predictor at each stage.

\subsection{Composite analysis}

To further test the predictors selected in the regression models, composite analyses are undertaken for high and low years of the predictors selected in the regression analysis, together with some predictors that were rejected either due to multicollinearity or though being marginally less significant than the predictor selected for the regression model. High (low) years are taken as the highest (lowest) third of values from the time series of the predictor. The difference in the jet metrics between high and low years of the predictor is calculated, together with their differences from climatological values. The composites are based on the longest time series for which the predictor is available, to maximise the number of years in the composite. Thus where a predictor is available for the period 1872-2012, this is the jet metric or SLP series that is used to produce the composite. Sea-ice composites are taken for the period 1956-2012 and snow and tropical precipitation composites are taken over 1980-2012. Sensitivity tests using division by quartiles and medians reveal no qualitative difference in results according to the stratification used (not shown). Results are tested for significance using the two-sided Mann-Whitney-Wilcoxon test, as some samples are too small for a conventional $t$ test and no assumptions have to be made about the normality of the data. Some predictors not identified as significant in the regression analysis may well be significant in the composite analysis. This may be a result of composite analysis being more appropriate for analysing non-linear relationships, or alternatively could be due to chance. The non-linear aspect of associations can be identified by comparison of each of the high and low composites with climatological values. If one of these differences is significant and the other is not, it is suggestive of an asymmetric relationship whereby one extreme of predictor occurrences (either high or low) has a greater potential influence than anomalies of the opposite sign.

As the years selected for high and low values are based on the predictor time series, any uncertainty associated with the ensemble mean for 20CR will have no impact on the years selected.

SLP plots showing SLP differences between high and low predictor years are provided where significant differences are identified in the jet metric composites. Significance values are shown, with adjustments made for spatial autocorrelation using the False Discovery Rate (FDR, Benjamini and Hochberg 1995; Wilks 2006), as this method takes account of the magnitudes of individual $p$ values relative to the significance level of the global null hypothesis. The FDR is the expected fraction of apparently significant tests whose null hypotheses are true. It is notable that for composites from the longer time series, the effect of the larger composite size (47 years) is to increase the 
Table 1 Regression coefficients for predictors of jet speed and latitude

\begin{tabular}{|c|c|c|c|c|c|c|c|c|c|c|c|c|c|c|c|c|}
\hline \multirow[b]{3}{*}{ month } & \multirow{3}{*}{$\begin{array}{c}\begin{array}{c}\text { Intercept } \\
\text { coefficient }\end{array} \\
\text { NA }\end{array}$} & \multirow{3}{*}{$\begin{array}{c}\begin{array}{c}\text { Tropical } \\
\text { rainfall }\end{array} \\
\text { AR } \\
1 \\
\end{array}$} & \multicolumn{4}{|c|}{ solar } & \multicolumn{6}{|c|}{ SST } & \multicolumn{2}{|c|}{ cryosphere } & \multirow[b]{3}{*}{$\mathbf{R}^{2}$} & \multirow[b]{3}{*}{$\mathbf{x v R}^{2}$} \\
\hline & & & \multirow{2}{*}{$\begin{array}{c}\text { SS } \\
1 \\
\end{array}$} & \multirow{2}{*}{\begin{tabular}{|c|} 
lead1 \\
8 \\
\end{tabular}} & \multicolumn{2}{|c|}{ lead3 } & \multirow{2}{*}{$\begin{array}{c}\text { N3.4 } \\
6 \\
\end{array}$} & \multicolumn{2}{|c|}{ AMO } & \multicolumn{3}{|c|}{ tripole } & \multirow{2}{*}{\begin{tabular}{|c|} 
Arctic SI \\
9 \\
\end{tabular}} & \multirow{2}{*}{$\begin{array}{c}\text { BKI } \\
11\end{array}$} & & \\
\hline & & & & & 2 & 10 & & 1 & 8 & 3 & 5 & 11 & & & & \\
\hline \multicolumn{17}{|l|}{ speed } \\
\hline 1980 & 10.45 & 0.25 & 0.27 & & & & & & & & & 0.20 & & & 0.47 & 0.33 \\
\hline 1956 & 10.50 & & & 0.17 & & & & & & & & & -0.24 & & 0.19 & 0.10 \\
\hline 1871 & 10.50 & & & & & & & & -0.72 & & -0.09 & & & & 0.09 & 0.05 \\
\hline \multicolumn{17}{|l|}{ latitude } \\
\hline 1980 & 51.06 & & & & & & & & & 0.53 & & & & 0.80 & 0.44 & 0.35 \\
\hline 1956 & 49.89 & & & & & 0.47 & & -2.49 & & & & & & 1.03 & 0.38 & 0.28 \\
\hline 1871 & 49.37 & & & & 0.63 & & -0.55 & & & & & & & & 0.10 & 0.06 \\
\hline
\end{tabular}

The intercept coefficient A is found in the first column. AR Tropical Atlantic rainfall, $S S$ solar cycle, lead 1, 3 solar cycle leading by 1, 3 years, AMO Atlantic Multidecadal Oscillation, SI total Arctic sea ice, BKI Barents-Kara Sea ice. Grey shading indicates that the predictor is not available for that time series. Empty cells indicate that the predictor was not selected for the regression model. Only drivers that were found to be significant in the regression models are included in this table

significance of the results, such that when $p$ values are adjusted using the FDR, areas of significance are evident. However, for the 1956 and 1980 time series, composite sizes are 19 and 11 years respectively. While areas of the maps appear significant prior to adjustment, these disappear following the application of the FDR. Given that longer series show significance, this is considered to be an artifact of the short time series due to reduced degrees of freedom, rather than necessarily an indicator of no significance. Thus results are presented and discussed for these shorter time series with unadjusted significance levels on the maps.

\subsection{Wavelet coherence analysis}

Relationships in geophysical time series often appear to be non-stationary, yet may exhibit apparent periodicities which are intermittent. It is useful to examine how the periodicities of two time series co-vary and this can be undertaken using wavelet coherence (WTC) plots (see Grinsted et al. 2004 for details). Plots produced indicate how the continuous wavelet transforms of two time series co-vary, analogous to correlation, with values from 0 to 1 . Arrows on the plot show the phase relationship of the time series, such that even when common power is low, periods of covariance with a common phase relationship can be identified, suggestive of causality.

It should be noted that, as with the composite plots, there are limitations when using wavelet coherence analysis for the shortest time series. The longest period detectable for the 1980 series is just over 11 years, precluding analysis of periodicities longer than this. The cone of influence has a disproportionately large influence, further reducing the usefulness of the results (see Torrence and Compo 1998 for details). Only periodicities of 5 years or less can be analysed for more than half of the time series. In order to minimize this effect, analysis has been carried out for the longest possible time series over which the predictor dataset is available, even if it only appeared as a significant predictor in the shorter time series.

\section{Results}

Here we present the results of these analyses. The regression models that are developed are discussed in general terms in Sect. 4.1. In Sect. 4.2 we present results for each predictor separately. Associations with jet speed and latitude are discussed together with evidence from regression, composite and wavelet coherence analyses.

\subsection{Regression models}

Regression coefficients, $\mathrm{R}^{2}$ and $\mathrm{xvR}^{2}$ values are presented in Table 1, for the predictors selected as being significant in the regression models. The table can be used to construct the regression models as the intercept coefficient, $A$ is included, together with the coefficients of the relevant predictors. The month for which the predictor is selected is also shown. Some predictors are selected independently for more than one time series regression model: for example November sea-ice is selected as a significant predictor for both the 1956 and 1980 latitude models, while not being available for the 1872 model. Similarly a solar predictor with a lead of three years appears to be significant for the 1956 and 1872 latitude models, although different months are chosen as predictors in each case. Such predictors are likely to be more robust predictors of jet metrics, because they are selected independently in different models. Table 1 also highlights the limitations of certain predictors which are not available for selection for the longer time series models, such as tropical rainfall. These results need treating with greater caution. Some predictors such as the North Atlantic SST tripole show persistence such that significant regression relationships occur between the predictor and jet metric over a number of months. Here the 
most significant relationships are used in the regression analysis.

Comparisons of the best-fit regression models with the 20CR time series of jet metrics are shown in Figs. 4, 5. In general, the models show a good representation of the direction of change of the jet metric from one year to the next, although as the time series lengthen and fewer predictors are available for model fitting, the amplitude becomes less well represented. The jet-speed and -latitude regression models are able to account for just over a third of the jet variability for the 1980 time series $\left(\mathrm{xvR}^{2}=0.33\right.$ for jet speed and 0.35 for latitude) while for the 1956 time series, jet-latitude regression models give much better representations than those for speed $\left(\mathrm{xvR}^{2}=0.28\right.$ compared with 0.10 ), and both speed and latitude models for the 1872 regression models are very weak $\left(\mathrm{xvR}^{2} 0.05\right.$ and 0.06 respectively). $x v R^{2}$ values for jet speed (1980) and latitude (1980 and 1956) are statistically significant at $p \leq 0.05$ through calculation of the F statistic. While the 1956 and 1980 models show in-phase variability with the observed jet metrics, the amplitudes of variability are reduced, particularly for the longer time series. The addition of a further random component to account for internal chaotic variability could allow estimation of extremes. The 1872 models are of little value, having a greatly reduced amplitude, and very small $R^{2}$ values, a consequence of limited availability of important predictors.

A number of years are poorly represented; for example 1993 and 2003 for jet latitude and 1997 for jet speed. From 2008 the 1980 model estimates the latitude of the summer jet to be too far north on a consistent basis. Extreme summer years such as 1976, 2003 (warm and dry in western Europe) and 2007 and 2012 (cooler and wetter in western Europe) do not appear as extremes in the jet speed observations, while 1976 and 2012 are the third highest and third lowest jet latitude in the observations for 1956-2012. 2003, while hot and dry, shows a relatively low jet latitude, indicative of conditions which were influenced by factors other than the jet stream such as soil moisture. 1976 and 2012 are not particularly well represented in the models (Figs. 4, 5).

\subsection{Relationships between jet metrics and potential predictors}

\subsubsection{Tropical rainfall}

In the regression analysis, this predictor is only significant for JJA jet speed (January AR, Table 1), and an additional predictor (July WIR) is further analysed in the composite analysis as this predictor is eliminated from the regression analysis due to multicollinearity (Table 2). The relationship is positive in both cases (increased rainfall anomalies associated with increased jet speed, and vice versa). This

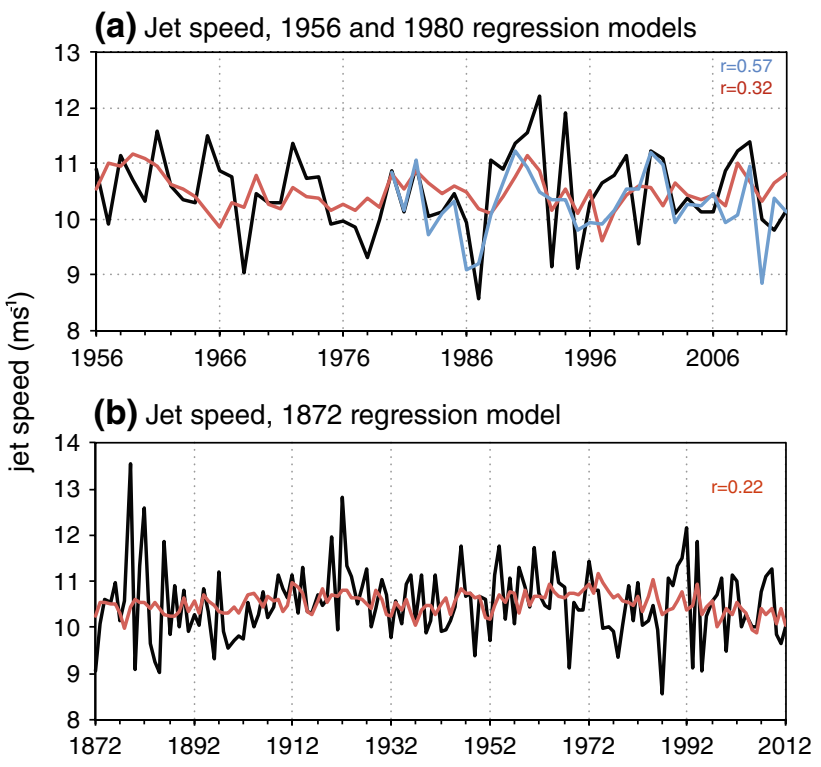

Fig. 4 JJA zonal jet speed from 20CR and regression models. a black 20CR, red 1956 model, blue 1980 model. b Black 20CR, red 1872 model. Correlation coefficients between the observed and predicted NAO are shown, significant at $p \leq 0.05$

(a) Jet latitude, 1956 and 1980 regression models

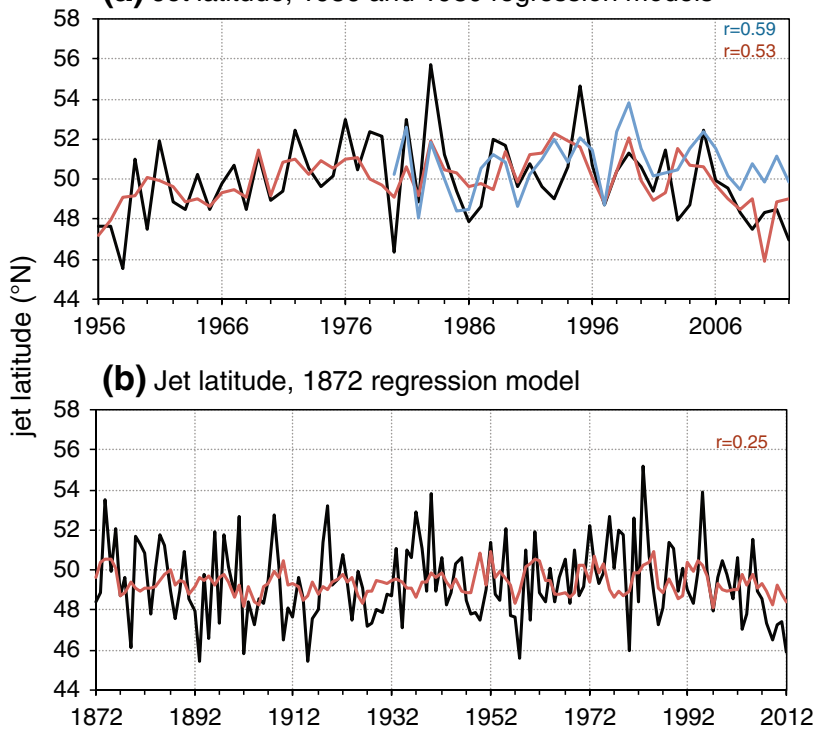

Fig. 5 JJA jet latitude from 20CR and regression models. a black 20CR, red 1956 model, blue 1980 model b black 20CR, red 1872 model. Correlation coefficients between the observed and predicted $\mathrm{NAO}$ are shown, significant at $p \leq 0.05$

is in agreement with AGCM results for winter (Hoerling et al. 2004). SLP composites confirm lower pressure to the north and higher pressure to the south in the Atlantic, associated with higher rainfall anomalies, but the pattern is not typical of the SNAO, the centres of action being orientated 
Table 2 Composite JJA jet stream metrics from high and low years of regression analysis, based on terciles with $p$ values for the high/low, high/climatology and low/ climatology differences

\begin{tabular}{|c|c|c|c|c|c|}
\hline Driver & High & low & $\mathrm{P}$ (high/low) & P (high/clim) & P (low/clim) \\
\hline \multicolumn{6}{|c|}{ (a) JJA jet speed $\left(\mathrm{ms}^{-1}\right)$ predictors composites ${ }^{\mathrm{a}}$} \\
\hline July WIR* & 10.74 & 9.83 & 0.01 & 0.44 & $\mathbf{0 . 0 2}$ \\
\hline January AR & 10.98 & 10.13 & 0.01 & 0.08 & 0.16 \\
\hline Solar & 10.58 & 10.61 & 0.63 & NA & NA \\
\hline Solar lead $2 *$ & 10.66 & 10.53 & 0.35 & NA & NA \\
\hline Solar lead4* & 10.45 & 10.57 & 0.37 & NA & NA \\
\hline August AMO & 10.24 & 10.63 & $\mathbf{0 . 0 1}$ & 0.14 & 0.64 \\
\hline May tripole & 10.35 & 10.81 & $3 \times 10^{-3}$ & 0.27 & 0.16 \\
\hline Nov tripole & 10.59 & 10.48 & 0.44 & NA & NA \\
\hline Sept Arctic SI & 10.17 & 10.77 & 0.02 & 0.22 & 0.26 \\
\hline \multicolumn{6}{|c|}{ (b) JJA latitude predictors $\left({ }^{\circ} \mathrm{N}\right)$ composites ${ }^{\mathrm{b}}$} \\
\hline Solar* & 49.49 & 48.99 & 0.26 & NA & NA \\
\hline Solar lead $1 *$ & 49.63 & 49.00 & 0.18 & NA & NA \\
\hline Solar lead3 & 49.66 & 48.90 & 0.08 & NA & NA \\
\hline Solar lead4* & 49.83 & 48.91 & 0.04 & 0.44 & 0.30 \\
\hline Solar lead $5^{*}$ & 49.92 & 48.97 & 0.02 & 0.24 & 0.34 \\
\hline June N3.4 & 49.16 & 49.62 & 0.13 & NA & NA \\
\hline January AMO & 49.35 & 49.53 & 0.65 & NA & NA \\
\hline March tripole & 49.59 & 49.26 & 0.52 & NA & NA \\
\hline November BKI & 50.51 & 48.40 & $1 \times 10^{-3}$ & 0.08 & 0.04 \\
\hline Sept Arctic SI & 50.10 & 48.68 & 0.03 & 0.26 & 0.20 \\
\hline Feb Am snow* & 48.09 & 50.48 & 0.02 & 0.02 & 0.22 \\
\hline
\end{tabular}

$p$ values are derived from a two-tailed Mann-Whitney-Wilcoxon test. Columns show $p$ values for the difference between high and low years, high years and climatology and low years and climatology. Significant values $(p \leq 0.05)$ are in bold. Drivers denoted * were excluded from regression analysis due to multicollinearity but have been included in composite analysis. WIR West Indian Ocean rainfall, $A R$ tropical Atlantic Rainfall, SI Arctic sea ice, BKI Barents-Kara sea ice, Am snow North American snow anomalies. Composites are taken from the longest time series for which the predictor is available, to maximise the number of years in the composites

Significance values are to two decimal places with the exception of the very small $p$ values for May tripole/ jet speed and November BKI/jet latitude

a Climatological average 1981-2010: $10.49 \mathrm{~ms}^{-1}$

${ }^{\text {b }}$ Climatological average, 1981-2010: $49.52^{\circ} \mathrm{N}$ southwest-northeast (Fig. 6a, b). The July WIR pattern is reminiscent of a planetary wavetrain arcing over the Aleutians, Hudson Bay and the North Atlantic (Fig. 6b), but also shows a large pressure anomaly to the north of Norway. These features are also evident at the 500GPH level (not shown). WTC plots are largely inconclusive, for reasons discussed above, although there are indications of the time series co-varying at 11 year periodicity and from 1 to 3 year periodicity from 1985 to 1995 for JJA speed/January AR (Fig. 6c) and there is covariance with July WIR at 8-11 years in the mid 1990s (Fig. 6d). In Table 2, the low July WIR anomalies are significantly different from climatological values, whereas the high anomalies are not, indicating an asymmetric association with the low rainfall anomalies exerting a greater potential influence than the high anomalies. The difference between high and low anomalies is significant.

\subsubsection{Solar influences}

While a synchronous solar signal is identified as a potential predictor of JJA speed variability for the 1980 time series (Table 1), this is not identified as significant in composite analysis (Table 2). However, a significant positive association between the leading solar cycle and JJA jet latitude is identified both in regression and composite analysis (Tables 1,2), with the SLP composite showing a weak positive SNAO like pattern for a high solar signal (Fig. 7a). The solar cycle with a lead of 3 years is identified as most significant in the regression analysis while in composite analysis, where the solar signal is considered in isolation from other predictors, the leads of 4 and 5 years are more significant. This lagged association is evident in winter in a number of recent studies (Scaife et al. 2013; Gray et al. 2013; Andrews et al. 2015). The arc of high-pressure 
(a) SLP differences janAR high-low years

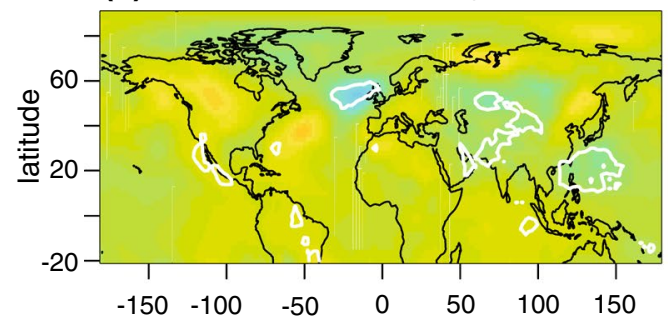

(b) SLP differences juIWIR high -low years

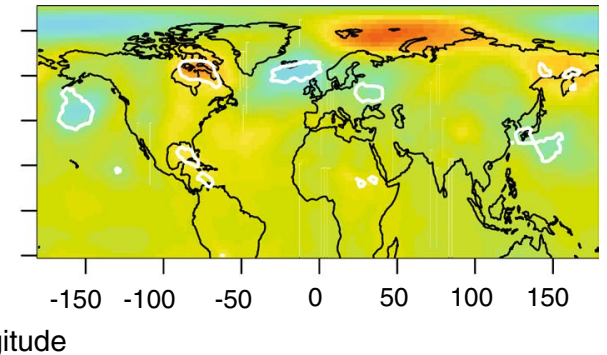

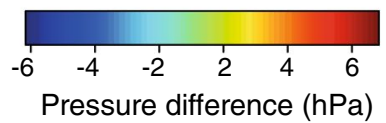

(c) janAR /JJA speed WTC

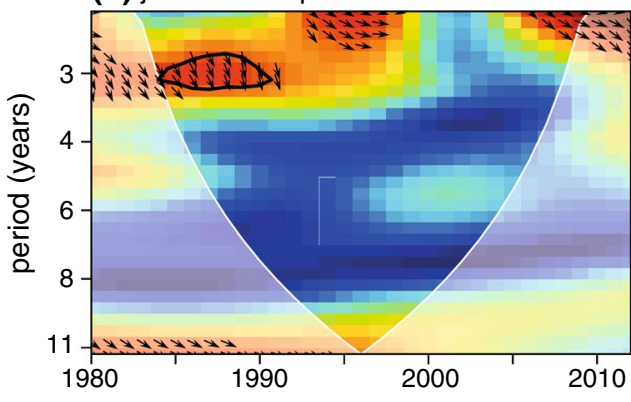

(d) juIWIR /JJA speed WTC

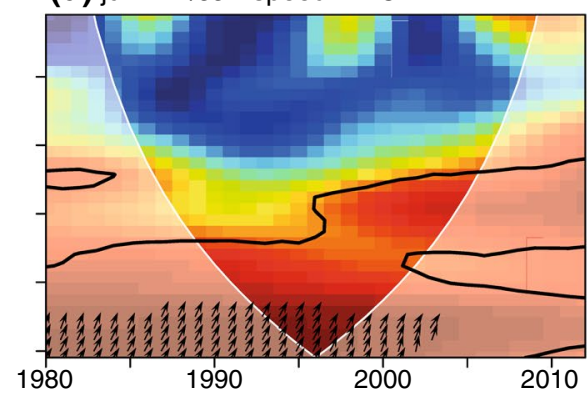

year

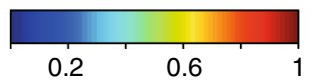

squared wavelet coherence

Fig. 6 a, b SLP composites for tropical precipitation predictors of summer jet metric variability, high minus low years. Note that white significance contours $(p \leq 0.05)$ are unadjusted and for guidance only. c, d Squared wavelet coherence between jet metrics and significant tropical rainfall regions identified from regression and composite analysis. The $5 \%$ significance level against a red noise background is shown by the black contour. The semi-transparent region shows the cone of influence. Arrows show the relative phase relationship ( $\rightarrow$ inphase; $\leftarrow$ anti-phase; $\uparrow$ predictor leads by $\pi / 2 ; \downarrow$ predictor leads by $3 \pi / 2$. Arrows are shown for $\mathrm{z}$ values greater than 0.9 anomalies associated with a leading solar signal extending from the mid Atlantic across the UK and into Eastern Europe bears close resemblance to the pattern identified for winter (Gray et al. 2013, their Fig. 4, at leads of three to 5 years), although it is reduced in extent eastwards and not identified as significant here, possibly a result of the different methodologies used. Sustained significant positive correlations are found between the leading solar signal and JJA latitude for the 1872 time series, between 32 and 56 months (Fig. 8). Correlations are at a similar level for the shorter time series but are not significant due to the reduced degrees of freedom.

The WTC plot (Fig. 7b) shows some common coherence around a period of 11 years, from 1890 to 1920, with the solar signal leading jet latitude by a consistent $\pi / 4$ radians, with weaker indications of a similar relationship between 1950 and 1980, where the relationship is in phase. The breaks in coherence could be due to solar signals being masked by other predictors, or due to fluctuations in the strength of the solar cycle.

\subsubsection{SST influences}

SST influences from the Atlantic (AMO and tripole) and the Pacific (El Niño) are potential predictors of jet variability, although in this analysis no significant evidence was found of an El Niño influence in the summer months. A significant association was found for the 1872 regression model only (Table 1), not supported by composite analysis (Table 2). This is likely due to the phase locking of El Niño to the annual cycle, reaching maximum strength in the winter months and the absence of a summer stratospheric teleconnection.

4.2.3.1 AMO The August AMO is identified as a significant predictor of JJA jet speed in the 1872 regression model 
(a) SLP differences high solar 5 lead-low solar 5 lead
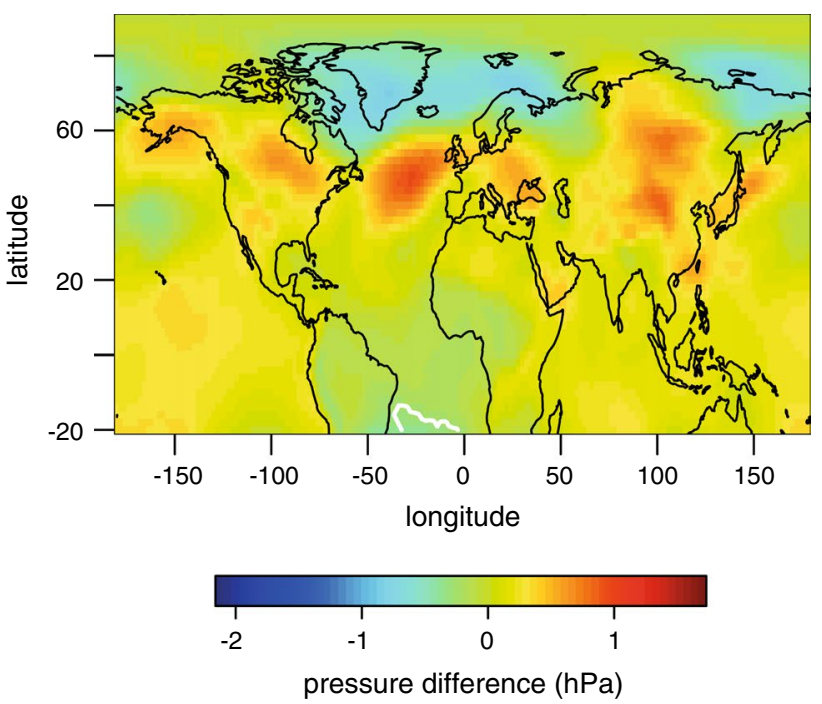

(b) solar 5 lead /JJA latitude WTC

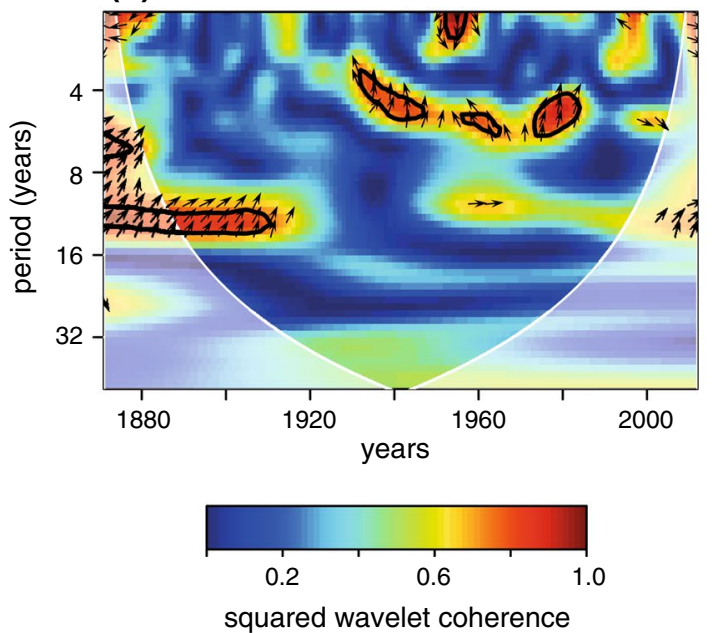

Fig. 7 a As for Fig. 6a, b, but for solar influences, high minus low years SLP composite. Here the white significance contours $(p \leq 0.05)$ are adjusted for the longer time series using the FDR. b As for Fig. $6 \mathrm{c}, \mathrm{d}$ except for wavelet coherence between solar influences and summer jet latitude

(Table 1) and its importance is confirmed by composite analysis and the SLP composite plots. A positive (negative) AMO is associated with lower (higher) jet speeds; the SLP composite map (Fig. 9a) showing anomalies of high pressure over Greenland and Iceland and low-pressure anomalies over the mid Atlantic and UK, for a high AMO, indicating a more negative SNAO-like pattern. This makes sense if the jet and the eddies are responding to SST gradients. There is a suggestion of a negative association with jet latitude for the 1956 regression model only (Table 1) but this is not apparent in the composite analysis (Table 2). The lower pressure area under high AMO conditions is shown to be significant $(p<0.05)$ across the width of the North Atlantic, covering the main area of SST that changes in unison with the AMO. The northwest-southeast alignment of the high and low anomalies between western Europe and Iceland is also reminiscent of the SNAO pattern (Folland et al. 2009) and agrees with the association of the positive (warm) AMO with wetter European summers and vice versa (e.g. Sutton and Dong 2012). The WTC plots are somewhat limited regarding the AMO as its periodicity (65-80 years) is beyond the range of periodicities covered by even the longer 1872 time series. Common coherence is found for periodicities of 6-16 years from 1955 to 2000, with the band of periodicities deemed as significant broadening through this period (Fig. 9b).

4.2.3.2 Atlantic tripole The May tripole is a significant predictor of summer jet speed in both regression analysis (1872) and composite analysis (Tables 1,2). The relationship between jet speed and November tripole identified in regression analysis is not found to be significant in composite analysis (Table 2) and is therefore not considered further. All months from November to April are significantly correlated with the May tripole value (e.g. the correlation between the previous November and that in May is 0.29 , $p \leq 0.05)$ and the March tripole is a significant predictor of jet latitude in the 1980 regression model (Table 1). The May tripole SLP composites show high pressure over the northern tripole node and low pressure over the southern node for a positive tripole, where the north-south ocean temperature gradient is reduced due to higher SST anomalies at the northern node compared with those at the central node (Fig. 10a). This pattern is reminiscent of a negative NAO in summer, but with the axis oriented southwest-northeast. SST appears to be leading the atmospheric response.

WTC plots show significant coherence at longer periodicities, with slowly varying or consistent phase relationships. May tripole/JJA speed show coherence at 12-16 years, 1890-1920 and 6-12 years during 1940-1975 (Fig. 10b). These correspond with the period for the tripole of around 11 years (Fan and Schneider 2012). There is a suggestion of a longer common periodicity with speed and the tripole at around 45 years.

\subsubsection{Cryospheric influences September Arctic Sea ice} (SI) and November Barents-Kara Seaice (BKI) essentially show the same pattern of a negative SNAO in summer following low ice extent in the previous autumn (Fig. 11a, b), linked to a southward displacement and strengthening of the jet, evident in regression models and composite analysis (Tables 1,2). The November BKI is associated with stronger SLP anomalies and it appears that low BKI anomalies are more influential on summer jet latitude than are high sea-ice anomalies, with low anomalies showing significant 


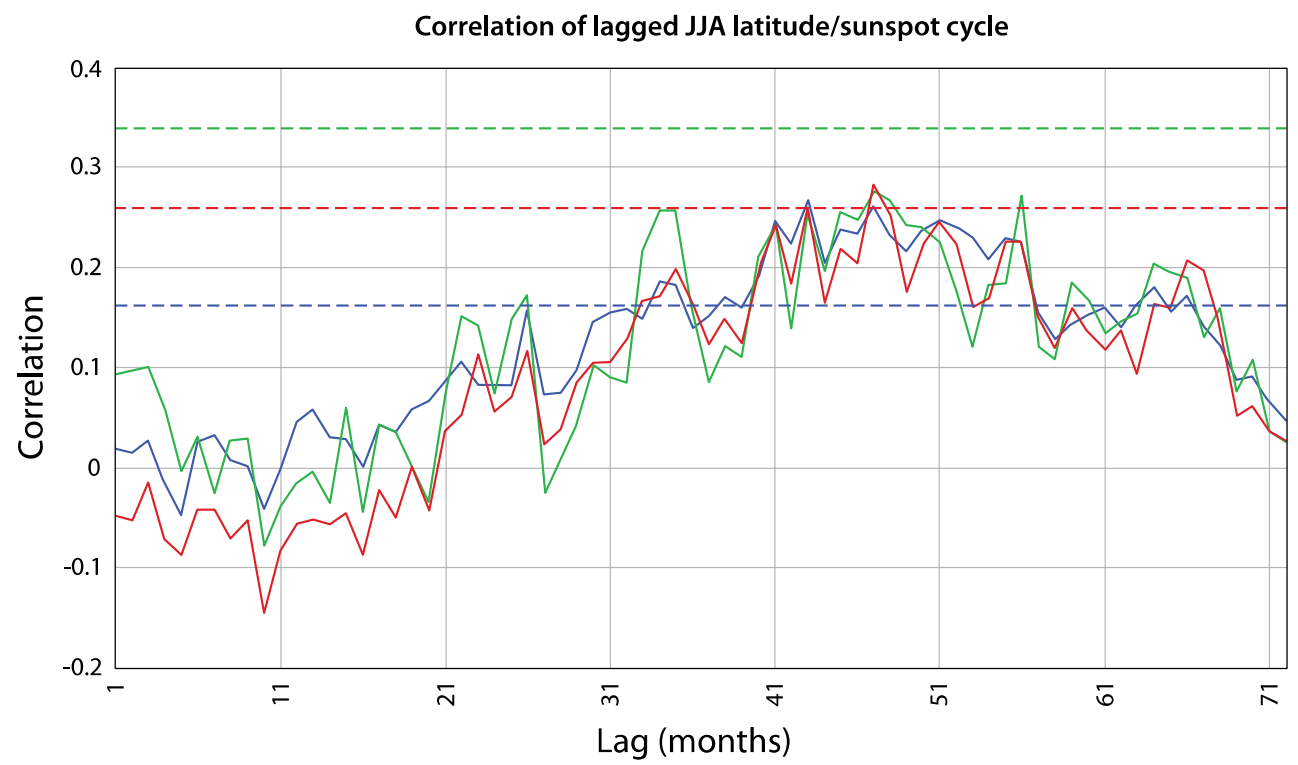

Fig. 8 Monthly correlation of sunspot cycle with lagged JJA latitude, 1872 time series (blue), 1955 (red) and 1979 (green). Dashed lines are $95 \%$ significance levels for respective time series

jet latitude differences from climatology (Table 2) and the difference between high-ice and low-ice composites is also significant. However, no significant evidence for a link with Sea of Okhotsk sea-ice (OSI) is found here, despite being suggested by Screen (2013) as a possible source of Northern hemisphere atmospheric variability.

WTC plots are limited in their effectiveness as sea-ice data were only used from 1956 (1980 for OSI), so only shorter periodicities of less than 16 years are detectable. Common coherence is found for summer jet speed/September Arctic sea-ice, for periodicities of 8-11 years, from 1985 to 2000, and for 5-8 years periodicities from 1978 to 1990 (Fig. 11c). Similarly, common coherence is found for summer jet latitude/November BKI 6-8 years for 19801990, 3-4 years for 1985-2000 (Fig. 11d). Significant shorter periodicities are also evident, with a constant or slowly varying phase relationship. The coherence does not seem to extend for more than 15 years, suggesting that seaice fluctuates in a less consistently periodic way at shorter timescales. This variability reflects the quasi-decadal oscillation evident in Arctic sea ice extent and its close coupling with the NAO (e.g. Wang et al. 2005; Mysak and Venegas 1998).

While snow anomalies do not appear as significant predictors in the regression models (Table 1), February North American snow anomalies are significant in the composite analysis (Table 2), suggesting an association between high (low) snow anomalies in February and a subsequent southward (northward) displacement of the summertime jet. The SLP composite plot indicates a positive (negative) SNAOlike pattern associated with low (high) snow anomalies
(Fig. 12a), and it is the high snow years that contribute most to this pattern, as differences in jet latitude between high snow years and climatological values are significant, while those for low snow years are not (Table 2). The difference between high- and low-snow anomalies is significant. This is not a case of positive snow anomalies persisting until summer, as the seasonal snow cycle for years with high and low February snow anomalies (Fig. 13) show that summer snow anomalies are very similar, irrespective of whether the February anomaly is high or low. The low (high) snow anomalies are accompanied by a strong positive (negative) temperature anomaly over North America extending upward to $300 \mathrm{hPa}$ (not shown), which persists into March and April with a northward displacement, with low temperature anomalies persisting over the Greenland/Baffin Bay region until summer. There is an interesting positive (negative) temperature anomaly at $70^{\circ} \mathrm{N}$ extending from the surface to $400 \mathrm{hPa}$, associated with the high (low) snow anomalies in February, a reversal of what has been found for the previous months (not shown). The low (high) snow anomalies are associated with a positive (negative) phase of the Arctic Oscillation (AO) and a cold (warm) stratospheric polar night jet in February (not shown). The strong cold stratospheric polar vortex will reduce the likelihood of cold air outbreaks over the eastern United States while a warm, weaker vortex will increase this possibility, and is therefore associated with high snow anomalies. However, low (high) February snow anomaly years are associated with prolonged periods with relatively low (high) values of the Greenland Blocking Index in August (GBI; Fang 2004; Hanna et al. 2013), favouring a positive (negative) SNAO 
(a) SLP differences, August AMO high - low years
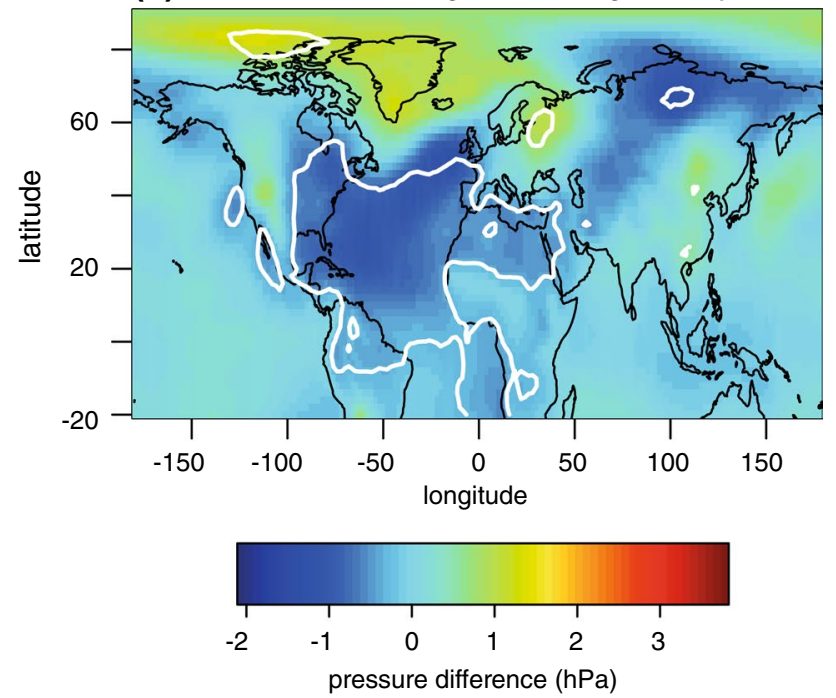

(b) augAMO /JJA speed WTC

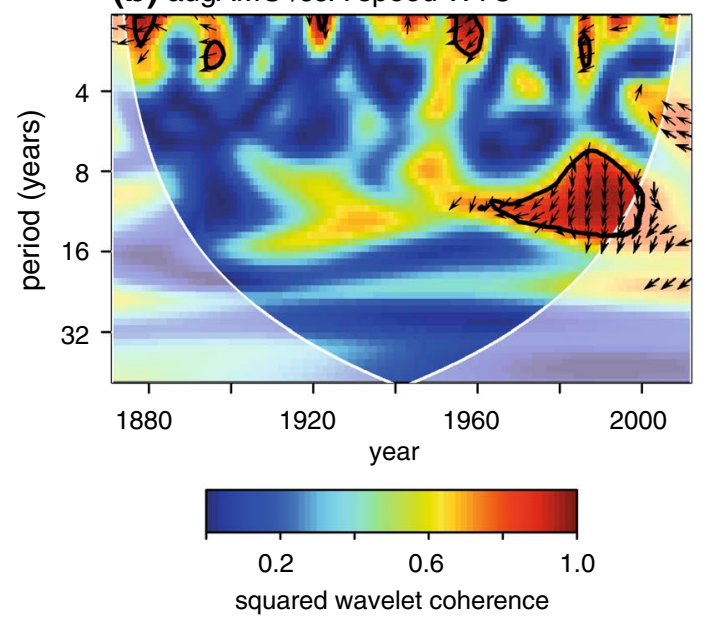

Fig. 9 a As for Fig. 6a, b but for August AMO high minus low years SLP composite. Here the white significance levels $(p \leq 0.05)$ are adjusted using the FDR. b As for Fig. 6c, d except for wavelet coherence between August AMO and summer jet speed

and northward (southward) jet displacement in summer. WTC shows common coherence at 3-4 years from 1992 to 2005, and a slowly varying phase relationship, with coherence becoming more significant at shorter periodicities ( $<3$ years) from 2000 to 2005 (Fig. 12d).

\section{Discussion}

The regression analysis indicates that the use of simple statistical models can explain up to $35 \%$ of summer jet stream variability, but tend to underestimate the amplitude of the variability. This proportion is consistent with the $30 \%$ of summer North Atlantic climate variability not explained (a) SLP differences May tripole high -low years
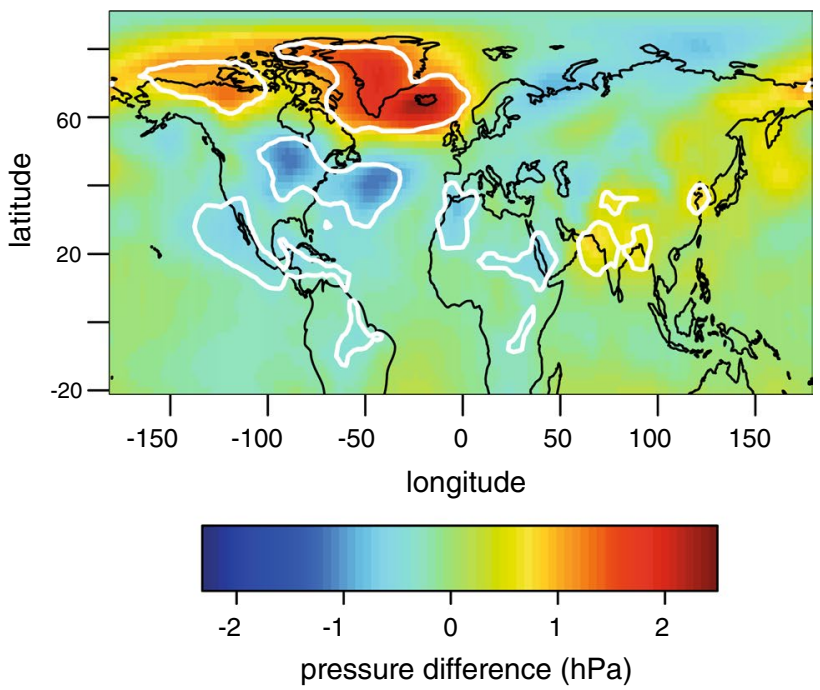

(b) May tripole /JJA speed WTC

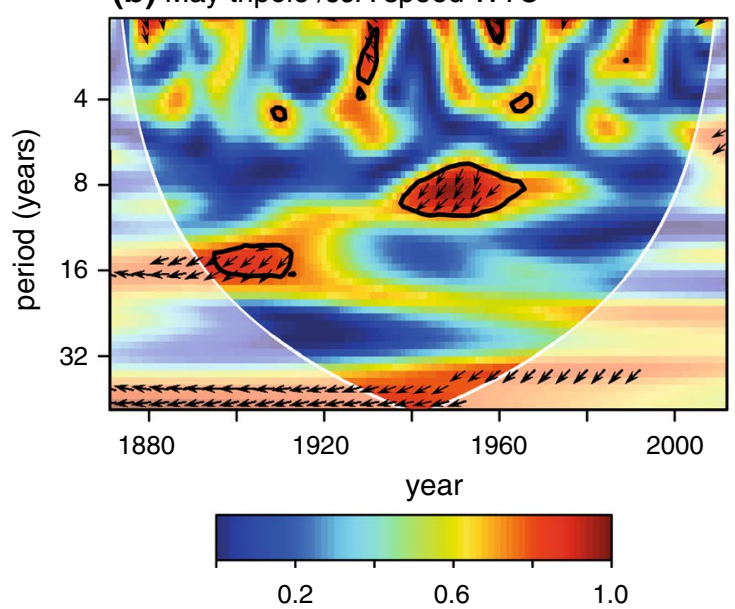

squared wavelet coherence

Fig. 10 a As for Fig. 6a, b but for May tripole high minus low years SLP composite. Here the white significance contours $(p \leq 0.05)$ are adjusted using the FDR. b As for Fig. 6c, d except for wavelet coherence between May tripole and summer jet speed

by internal atmospheric variability (Franzke and Woollings 2011). The models based on the shorter time series will be most useful in developing the predictability of jet metrics, as the amplitude is a better representation of observed amplitude. Together with composite analysis, there is agreement with suggested predictors of variability identified in the literature, such as the AMO (Knight et al. 2006; Folland et al. 2009; Sutton and Dong 2012) and insight is gained into a wider range of potential predictors, with implications for improving the predictability of the summer jet stream. However, there could also be non-linear interactions between predictors and jet metrics which will not be well captured by regression models. Composite analysis is 
(a) SLP differences sepSI low-high years

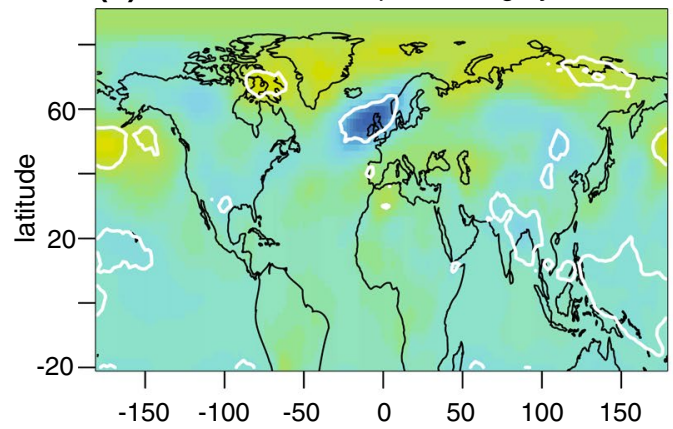

(b) SLP differences novBKI low-high years

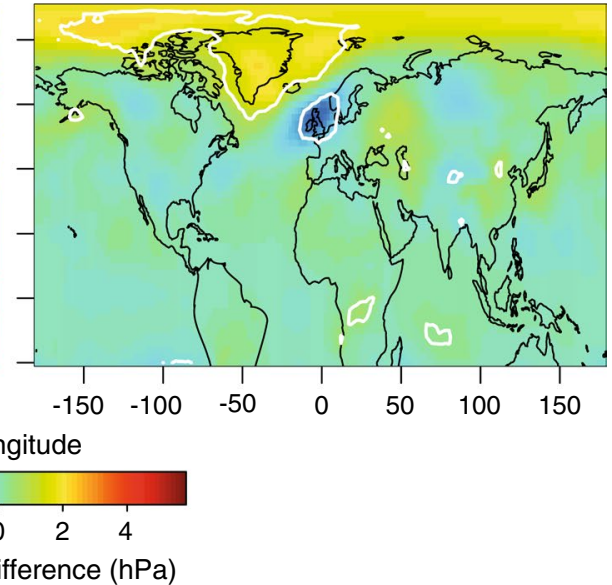

(c) sepSI /JJA speed WTC

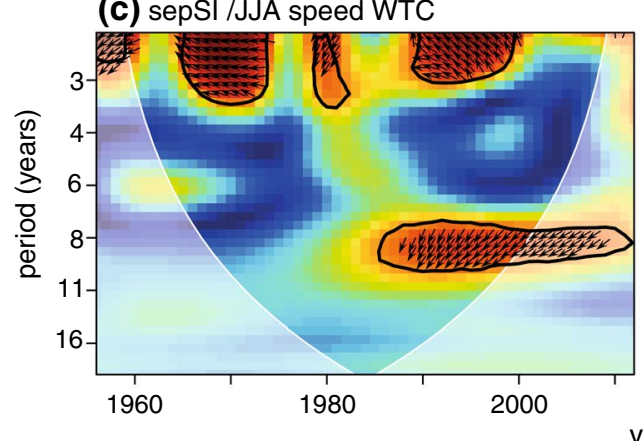

(d) novBKI /JJA latitude WTC

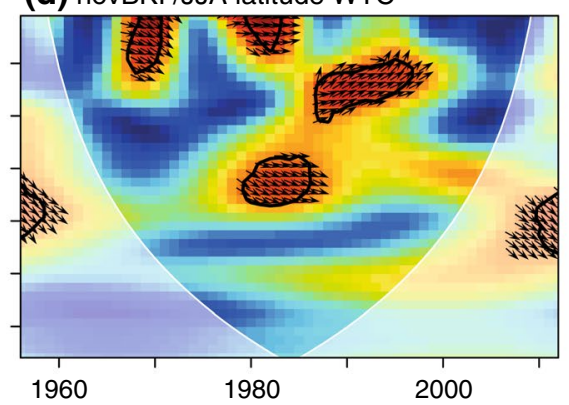

year

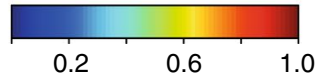

squared wavelet coherence

Fig. 11 a, b As for Fig. 6a, b except for sea-ice drivers of summer jet metric variability, low minus high years. Note that white significance contours $(p \leq 0.05)$ are unadjusted and for guidance only. $\mathbf{c}, \mathbf{d}$ As for
Fig. 6c, d except for wavelet coherence between sea-ice predictors and summer jet metrics

half of the summer SST anomalies, the remainder being driven by atmospheric variability, with the potential to impact on summer atmospheric circulation. This supports the results obtained here, indicating that spring Atlantic SST anomalies may offer some predictability for the summer Atlantic atmospheric circulation. While Dong et al. $(2013 \mathrm{a}, \mathrm{b})$ relate this to storm-track latitude and its eastward extension, here we find that the main impact is upon jet speed.

The identified relationship with the AMO links the positive phase of the AMO with a reduced jet speed and vice versa, whereas that described by Folland et al. (2009) related the positive AMO to a negative SNAO and a southward shift in the jet. These results are not inconsistent as the jet is likely to be weaker for a negative SNAO with a southward displaced and weaker storm track (Dong et al. 2013b), although the negative association with jet latitude is only significant in the 1956 regression model. 
(a) SLP differences N American snow low - high years

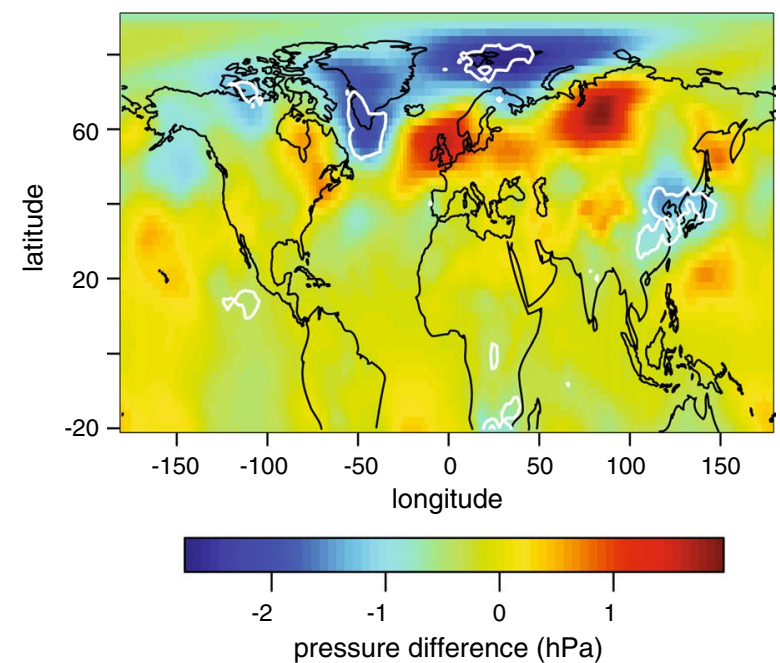

(b) feb N American snow anomalies /JJA latitude WTC

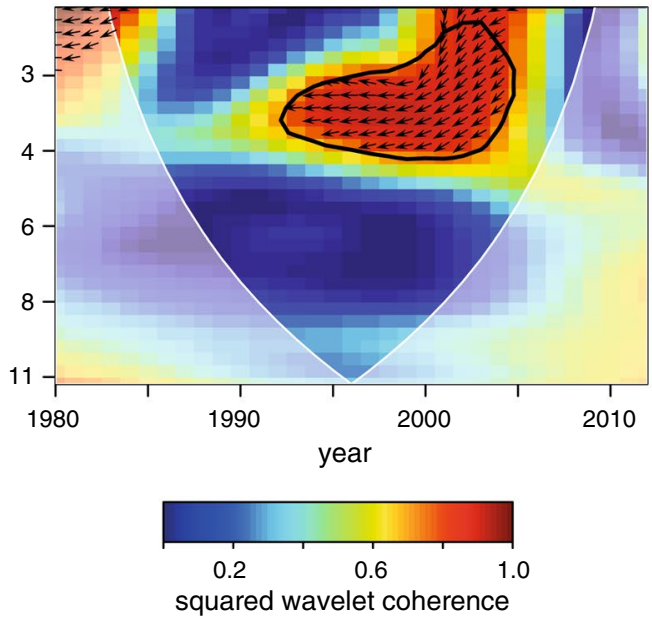

Fig. 12 As for Fig. 6a, b except for February North American snow predictor of jet metric variability, low minus high years. Note that white significance contours $(p \leq 0.05)$ are unadjusted and for guidance only. b As for Fig. 6c, d except for wavelet coherence between February North American snow and summer jet latitude

There is no significant ENSO influence detected in summer, which may reflect the absence of the stratospheric teleconnection whereby the strength of the stratospheric polar vortex, which can be affected by ENSO events, is able to exert a downward influence on the tropospheric atmospheric circulation in winter (e.g. Bell et al. 2009). This also reflects the annual cycle as ENSO events usually peak in strength in the winter months, having started in the previous spring.

Evidence for a solar influence is stronger for summer jet latitude than for speed. The question of solar cycle impact on climate has been controversial and solar signals in atmospheric variability have not been detected on a consistent basis, with much work, it has been suggested, relying on inadequate and non-robust statistics (Lockwood 2012). The importance of lagged correlations supports the analysis of Scaife et al. (2013) and Gray et al. (2013) although those studies focus on winter. Here the relationship is weaker, but shows a similar spatial distribution and lag, with high pressure anomalies in the central Atlantic and arcing across central Europe (Fig. 6a) associated with high solar cycle activity, perhaps reflecting seasonal variability in the link. This suggests summer impacts during the interannual buildup and therefore persistence of the solar signal in the Atlantic ocean, during which the atmospheric response increases through atmosphere-ocean coupling (Scaife et al. 2013; Gray et al. 2013) although it is interesting to note that while the predominant influence of SST anomalies above is on jet speed, here the association is with latitude.

Sea-ice concentration from the preceding autumn is associated with both summer jet speed and latitude, with total Arctic sea-ice associated with speed, while the regional impact from the Barents-Kara Seas is stronger with jet latitude. Little work has been done on the potential for summer atmospheric variability to be influenced by the previous autumn's sea ice concentration, and this merits further study. The mid-latitude atmospheric response in summer may be influenced by preconditioning of SST from the previous autumn sea-ice (Blanchard-Wrigglesworth et al. 2011). Wu et al. (2013) have identified a link between winter-late spring low sea-ice concentration anomalies in the Hudson Bay -Labrador Sea associated with anomalous atmospheric wavetrains leading to reduced geopotential heights and increased summer precipitation over western Europe, associated with a southward-displaced jet stream. The sign of the relationship in this study is the same, but the lead-time for our analysis is much longer, the signal appearing to survive the winter. There is evidence to suggest that BKI may be influenced by subsurface ocean temperatures with a lead-time of over a year (Nakanowatari et al. 2014) so longer leads and lags are being identified. The jet-speed association with the previous autumns's sea-ice is negative, indicating an increased JJA wind speed with decreased autumn ice. As this correlation is with total Arctic sea ice, the relationship could be a result of other areas of sea-ice coming into play, which do not exhibit the positive correlation with the jet stream, such as the Labrador Sea/Baffin Bay. This area is well known for showing a typically opposite relationship with the NAO to that shown with sea-ice east of Greenland, albeit a consequence of NAO forcing of sea-ice (e.g. Deser et al. 2000), but with potential for feedback to the atmosphere as indicated above.

The association with February, rather than spring, snow cover anomalies is puzzling, as anomalies in high and low years are very similar for spring and summer and there is scope for further work to identify a mechanism that may 


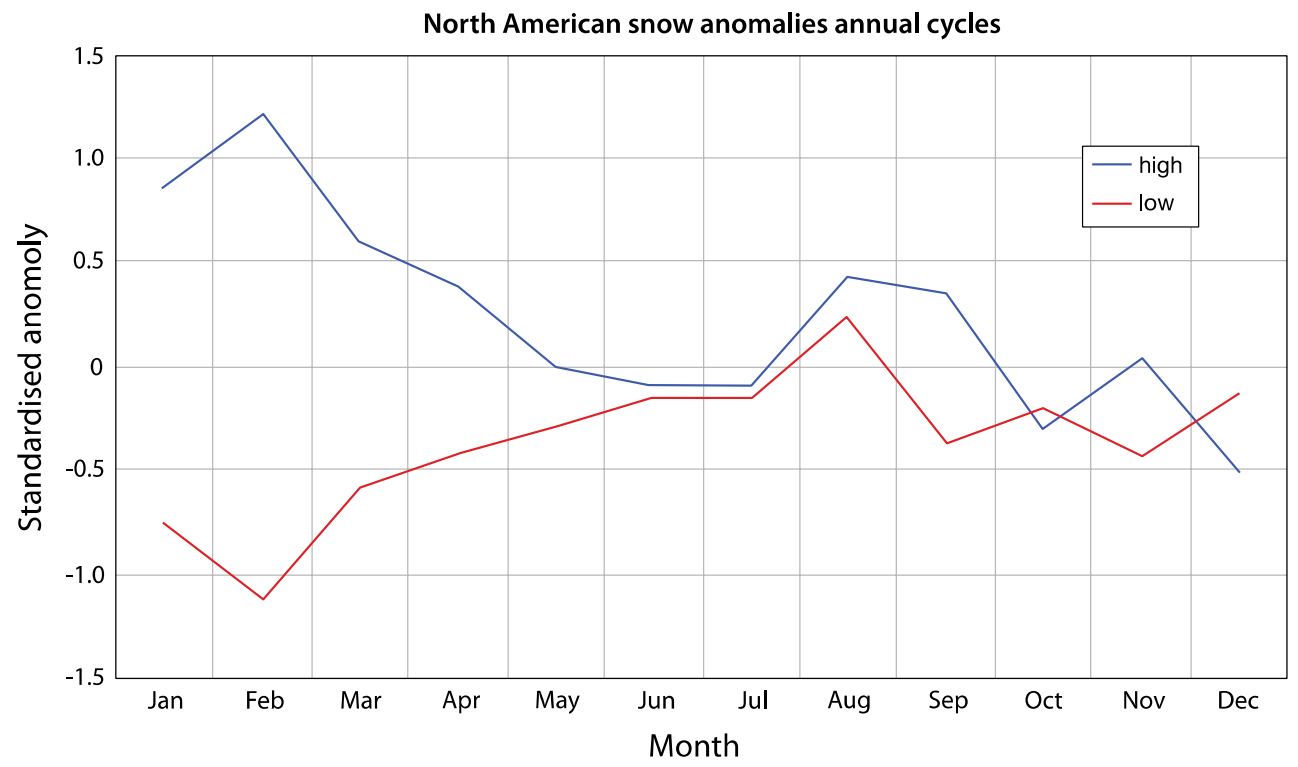

Fig. 13 Seasonal cycles of North American snow anomalies for February high snow anomaly years and February low snow anomaly years, 1980-2012

be involved with both snow anomalies and summer jet variability. It is possible that the level of blocking in the Greenland region is an influence both on snow anomalies and the summertime jet or that this feature simply occurred by chance. Matsumura et al. (2014) find that early Eurasian snow melt can lead to a negative Arctic Oscillation in summer; although this is an opposite result to that identified here, it supports the possibility of a spring snow cover impact upon summer atmospheric circulation patterns. However, the time and location of snow anomalies is different.

\section{Conclusions}

A number of potential predictors of summer jet stream variability have been identified, and simple linear models are able to explain up to $35 \%$ of JJA jet stream variability, although it must be stressed that internal atmospheric variability of the jet stream may be high and these observational analyses cannot demonstrate causality. Regression models capture the sign of much of the interannual variability, but are less effective over the longer time period of the 20CR, presumably due to more limited availability of potential predictor time series, and increased uncertainty in the earlier part of the jet time series derived from 20CR. The amplitude of variability is less than that observed, particularly for the longer time series. Composite analysis identifies significant relationships between predictors and jet metrics, reinforcing the results of the regression analysis, while suggesting further linkages not revealed by regression, perhaps due to non-linear relationships. Wavelet coherence analysis provides complementary information about phase relationships and changing of common periodicities over the time series, but highlights the fact that apparent relationships are far from uniform in the observational record. We note again that internal variability of the jet itself is likely to be important. Identification of different predictors over different time periods reflects possible nonstationarity, or the masking of predictors by other signals or internal atmospheric variability.

A significant development in this study is the decomposition of predictors of jet latitude and speed rather than with the NAO. This approach has shown that predictors are associated with different impacts on jet variability, depending on their origin, thus revealing a more subtle pattern than suggested by analysis of NAO variability alone. SST predictors exert a greater influence on jet speed, while lagged solar and seaice factors impact upon latitude, reduced sea-ice in autumn being associated with decreased jet latitude and speed the following summer. A positive (negative) AMO decreases (increases) jet speed, while influences from tropical SST anomalies may be propagated by the excitation of planetary wave trains. Our study did not find a significant link between ENSO events and summer jet variability. A key question for future research is to identify physical mechanisms for the significant relationships identified here and to explain how different predictors impact upon different aspects of the jet stream. The use of climate models could enable predictors to be isolated and mechanisms to be identified.

While there is a significant amount of uncertainty in summer jet stream variability, and skill in dynamical forecasts 
for the North Atlantic summer is currently low, the evidence presented in this study suggests that there is a significant component of predictability in summer jet stream metrics and there is potential for using the predictors identified in this study in the forecasting of summer jet stream variability, although the magnitude of extreme events is likely to be underpredicted. Given the recent summer extremes experienced around the Atlantic basin, this predictability could have important societal, environmental and economic benefits. While a number of the links identified were expected from what was already known from the literature, other associations require further investigation into possible causal mechanisms, such as links between February snow anomalies or January tropical rainfall anomalies and the summertime jet, and relationships identified should be confirmed by a fully-coupled climate modelling approach.

Acknowledgments AAS was supported by the Joint DECC/Defra Met Office Hadley Centre Programme (GA1101). RJH, JMJ, EH and RE acknowledge funding support from the University of Sheffield Project Sunshine. RE is grateful to NSF, Hungary (OTKA, Ref. No. K83133). David McCutcheon helped with preparation of some of the figures. Support for the Twentieth Century Reanalysis Project dataset is provided by the U.S. Department of Energy, Office of Science Innovative and Novel Computational Impact on Theory and Experiment (DOE INCITE) program, and Office of Biological and Environmental Research (BER), and by the National Oceanic and Atmospheric Administration Climate Program Office. ERA-I data is available from ECMWF at http://www.ecmwf.int/. We thank the two anonymous reviewers for their valuable comments, which helped to improve the manuscript.

Open Access This article is distributed under the terms of the Creative Commons Attribution 4.0 International License (http://creativecommons.org/licenses/by/4.0/), which permits unrestricted use, distribution, and reproduction in any medium, provided you give appropriate credit to the original author(s) and the source, provide a link to the Creative Commons license, and indicate if changes were made.

\section{References}

Adler RF, Huffmann GJ, Chang A, Ferraro R, Xie P, Janowiak J, Rudolf B, Schneider S, Curtis S, Bolvin D, Gruber A, Susskind J, Arkin P (2003) The version 2 global precipitation climatology project (GPCP) monthly precipitation analysis (1979-present). J Hydrometeorol 4:1147-1167

Andrews MB, Knight JR, Gray LJ (2015) A simulated lagged response of the North Atlantic Oscillation to the solar cycle over the period 1960-2009. Environ Res Lett 10:054022. doi:10.1088/1748-9326/10/5/054022

Anstey JA, Davini P, Gray LJ, Woollings TJ, Butchart N, Cagnazzo C, Christiansen B, Hardiman SC, Osprey SM, Yang S (2013) Multi-model analysis of northern hemisphere winter blocking: model biases and the role of resolution. J Geophys Res Atmos 118:3956-3971. doi:10.1002/jgrd.50231

Bai J, Perron P (2003) Computation and analysis of multiple structural change models. J Appl Econom 18(1):1-22. doi:10.1002/Jae.659

Ballinger TJ, Sheridan SC, Hanna E (2014) Resolving the Beaufort Sea High using synoptic climatological methods. Int J Climatol 34:3312-3319. doi:10.1002/joc.3907
Barnes EA (2013) Revisiting the evidence linking Arctic amplification to extreme weather in midlatitudes. Geophys Res Lett 40:16. doi: $10.1002 /$ grl.50880

Barnes EA, Polvani LM (2015) CMIP5 projections of Arctic amplification, of the North American/North Atlantic circulation, and of their relationship. J Clim 28:5254-5271. doi:10.1175/ JCLI-D-14-00589.1

Bell CJ, Gray LJ, Charlton-Perez AJ, Joshi MM, Scaife AA (2009) Stratospheric communication of El Niño teleconnections to European winter. J Clim 22:4083-4096. doi:10.1175/2009J CLI2717.1

Benjamini Y, Hochberg Y (1995) Controlling the false discovery rate: a practical and powerful approach to multiple testing. J R Stat Soc B57:289-300

Black E, Blackburn M, Harrison G, Hoskins B, Methven J (2004) Factors contributing to the summer 2003 heatwave. Weather 59(8):217-223. doi:10.1256/wea.74.04

Blackburn M, Methven J, Roberts N (2008) Large-scale context for the UK summer floods in summer 2007. Weather 63(9):280-288

Bladé I, Liebmann B, Fortuny D, van Oldenborgh GJ (2012) Observed and simulated impacts of the summer NAO in Europe: implications for projected drying in the Mediterranean region. Clim Dyn 39:709-727. doi:10.1007/s00382-011-1195-x

Blanchard-Wrigglesworth E, Armour KC, Bitz CM (2011) Persistence and inherent predictability of Arctic sea ice in a GCM ensemble and observations. J Clim 24:231-250. doi:10.1175/20 10JCLI3775.1

Butler AH, Polvani LM, Deser C (2014) Separating the stratospheric and tropospheric pathways of El Niño-Southern Oscillation teleconnections. Environ Res Lett 9:024014

Cassou C (2008) Intraseasonal interaction between the MaddenJulian Oscillation and the North Atlantic oscillation. Nature 455:523-527. doi:10.1038/nature07286

Cayan D (1992) Latent and sensible heat flux anomalies over the northern oceans: driving the sea surface temperature. J Phys Oceanogr 22:859-881

Compo GP, Whitaker JS, Sardeshmukh PD, Matsui N, Allan RJ, Yin $\mathrm{X}$, Gleason BE Jr, Vose RS, Rutledge G, Bessemoulin P, Brönnimann S, Brunet M, Crouthamel RI, Grant AN, Groisman PY, Jones PD, Kruk MC, Kruger AC, Marshall GJ, Maugeri M, Mok HY, Nordli $\varnothing$, Ross TF, Trigo RM, Wang XL, Woodruff SD, Worley SJ (2011) The twentieth century reanalysis project. Q J R Meteorol Soc 137:1-28. doi:10.1002/qj.776

Coumou D, Rahmstorf S (2012) A decade of weather extremes. Nat Clim Change 2:491-496. doi:10.1038/NCLIMATE1452

Coumou D, Petoukhov V, Rahmstorf S, Petri S, Schellhuber H-J (2014) Quasi-resonant circulation regimes and hemispheric synchronization of extreme weather in boreal summer. Proc Natl Acad Sci USA 111(34):12331-12336. doi:10.1073/pnas.1412797111

Czaja A, Frankignoul C (1999) Influence of the North Atlantic SST on the atmospheric circulation. Geophys Res Lett 26(19):2969-2972

Czaja A, Marshall J (2001) Observations of atmosphere-ocean coupling in the North Atlantic. Q J R Meteorol Soc 127:1893-1916

Davini P, Cagnazzo C, Fogli PG, Manzini E, Gualdi S, Navarra A (2014) European blocking and Atlantic jet stream variability in the NCEP/NCAR reanalysis and the CMCC-CMS climate model. Clim Dyn 43:71-85. doi:10.1007/s003382-013-1873-y

Dee DP, Uppala SM, Simmons AJ, Berrisford P, Poli P, Kobayashi S, Andrae U, Balmaseda MA, Balsamo G, Bauer P, Bechtold P, Beljaars ACM, van de Berg L, Bidlot J, Bormann N, Delsol C, Dragani R, Fuentes M, Geer AJ, Haimberger L, Healy SB, Hersbach H, Hólm EV, Isaksen L, Kållberg P, Köhler M, Matricardi M, McNally AP, Monge-Sanz BM, Morcrette J-J, Park B-K, Peubey C, de Rosnay P, Tavolato C, Thépaut J-N, Vitart F (2011) The ERA-Interim reanalysis: configuration and performance of 
the data assimilation system. Q J R Meteorol Soc 137:553-597. doi:10.1002/qj.828

Deser C, Timlin MS (1997) Atmosphere-ocean interaction on weekly timescales in the North Atlantic and Pacific. J Clim 10:393-408

Deser C, Walsh JE, Timlin MS (2000) Arctic sea ice variability in the context of recent atmospheric circulation trends. J Clim 13:617-633

Deser C, Alexander MA, Timlin MS (2003) Understanding the persistence of sea surface temperature anomalies in midlatitudes. J Clim 16:57-72

Deser C, Alexander MA, Xie S-P, Philllips AS (2010) Sea surface temperature variability: patterns and mechanisms. Annu Rev Mar Sci 2:115-143. doi:10.1146/annurev-marine-120408-151453

Ding Q, Wang B (2005) Circumglobal teleconnection in the northern hemisphere summer. J Clim 18:3483-3505

Dong B, Sutton R, Woollings T (2013a) The extreme European summer 2012. [in "Explaining Extreme Events of 2012 from a Climate Perspective"]. Bull Am Meteorol Soc 94(9):S28-S32

Dong B, Sutton RT, Woollings T, Hodges K (2013b) Variability of the North Atlantic summer storm track: mechanisms and impacts on European climate. Environ Res Lett 8:034037. doi: $10.1088 / 1748-9326 / 8 / 3 / 034037$

Duchon CE (1979) Lanczos filtering in one and two dimensions. J Appl Meteorol 18:1016-1022

Efron B, Gong G (1983) A leisurely look at the bootstrap, the jackknife and cross-validation. Am Stat 37:36-48

Efron B, Tibshirani RJ (1993) An introduction to the bootstrap. Chapman and Hall, New York

Enfield DB, Mestas-Nunez AM, Trimble PJ (2001) The Atlantic multidecadal oscillation and its relationship to rainfall and river flows in the continental US. Geophys Res Lett 28:2077-2080

Fan M, Schneider EK (2012) Observed decadal North Atlantic tripole SST variability. Part I: weather noise forcing and coupled response. J Atmos Sci 69:35-50. doi:10.1175/JAS-D-11-018.1

Fang Z-F (2004) Statistical relationship between the Northern Hemisphere sea ice and atmospheric circulation during wintertime. In: Xhu X (ed) Observation, theory and modeling of atmospheric variability, World Scientific Series on Meteorology of East Asia. World Scientific Publishing Company, Singapore, pp 131-141

Ferguson CR, Villarini G (2014) An evaluation of the statistical homogeneity of the twentieth century reanalysis. Clim Dyn 42:2841-2866. doi:10.1007/s00382-013-1996-1

Folland CK, Knight J, Linderholm HW, Fereday D, Ineson S, Hurrell JW (2009) The summer North Atlantic Oscillation: past, present and future. J Clim 22:1082-1103. doi:10.1175/2008JCLI2459.1

Folland CK, Scaife AA, Lindesay J, Stephenson DB (2012) How potentially predictable is northern European winter climate a season ahead? Int J Climatol 32:801-818. doi:10.1002/joc.2314

Francis JA, Vavrus SJ (2012) Evidence linking Arctic amplification to extreme weather in mid-latitudes. Geophys Res Lett 39:L06801. doi:10.1029/2012GL051000

Francis JA, Vavrus SJ (2015) Evidence for a wavier jet stream in response to rapid Arctic warming. Environ Res Lett 10:014005. doi:10.1088/1748-9326/10/1/014005

Franzke C, Woollings T (2011) On the persistence and predictability properties of North Atlantic climate variability. J Clim 24:466472. doi:10.1175/2010JCLI3739.1

Gray LJ, Scaife AA, Mitchell DM, Osprey S, Ineson S, Hardiman S, Butchart N, Knight J, Sutton R, Kodera K (2013) A lagged response to the 11 year solar cycle in observed winter Atlantic/ European weather patterns. J Geophys Res Atmos 118:1340513420. doi:10.1002/2013JD020062

Grinsted A, Moore JC, Jevrejeva S (2004) Application of the cross wavelet transform and wavelet coherence to geophysical time series. Nonlinear Process Geophys 11:561-566
Haarsma RJ, Hazeleger W (2007) Extratropical atmospheric response to equatorial Atlantic cold tongue anomalies. J Clim 20:20762091. doi:10.1175/JCLI4130.1

Hall R, Erdélyi R, Hanna E, Jones JM, Scaife AA (2015) Drivers of North Atlantic Polar Front jet stream variability. Int J Climatol 35:1697-1720. doi:10.1002/joc.4121

Hanna E, Jones JM, Cappelen J, Mernild SH, Wood L, Steffen K, Huybrechts P (2013) The influence of North Atlantic atmospheric and oceanic forcing effects on 1900-2010 Greenland summer climate and ice melt/runoff. Int J Climatol 33:862-880. doi:10.1002/joc. 3475

Hanna E, Cappelen J, Fettweis X, Mernild S, Mote T, Steffen K, Wood L (2014) Atmospheric and oceanic climatic forcing of the exceptional Greenland Ice Sheet surface melt in summer 2012. Int J Climatol 34:1022-1037. doi:10.1002/joc.3743

Hanna E, Cropper TE, Jones PD, Scaife AA (2015) Recent seasonal asymmetric changes in the NAO (a marked summer decline and increased winter variability) and associated changes in the $\mathrm{AO}$ and Greenland blocking index. Int J Climatol. doi:10.1002/joc.4157

Hastie T, Tibshirani R, Friedman J (2009) The elements of statistical learning: data mining, inference and prediction, 2nd edn. Springer, New York

Hoerling MP, Hurrell JW, Xu T, Bates GT, Phillips AS (2004) Twentieth century North Atlantic climate change. Part II: understanding the effect of Indian Ocean warming. Clim Dyn 23:391-405. doi:10.1007/s00382-004-0433-x

Hoerling M, Schubert S, Mo K (2013). An interpretation of the origins of the 2012 central great plains drought. National Oceanic and Atmospheric Administration Drought Task Force. Available online: cpo.noaa.gov/ClimatePrograms/ModelingAnalysisPredictionsandProjections/MAPPTaskForcesd/DroughtTaskForce. aspx. Accessed 13 Aug 2015

Hoskins BJ, Karoly DJ (1981) The steady linear response of a spherical atmosphere to thermal and orographic forcing. J Atmos Sci 38:1179-1196

Hurrell JW (1995) Decadal trends in the North Atlantic OscillationRegional temperatures and precipitation. Science 269:676-679

Hurrell JW, Kushner Y, Ottersen G, Visbeck M (2003). The North Atlantic Oscillation: climatic significance and environmental impact. Geophysical monographs 134: American Geophysical Union

Kalnay E, Kanamitsu M, Kistler R, Collins W, Deaven D, Gandin L, Iredell M, Saha S, White G, Woollen J, Zhu Y, Cheliah M, Ebisuzaki W, Higgins W, Janowiak J, Mo KC, Ropelowski C, Wang J, Leetmaa A, Reynolds R, Jenne R, Joseph D (1996) The NCEP/ NCAR reanalysis project. Bull Am Meteorol Soc 77(3):437-471

Kaplan A, Cane M, Kushnir Y, Clement A, Blumenthal M, Rajagopalan B (1998) Analyses of global sea surface temperature 18561991. J Geophys Res 103:18567-18589

Kidston J, Scaife AA, Hardiman SC, Mitchell DM, Butchart N, Baldwin MP, Gray LJ (2015) Stratospheric influence on tropospheric jet streams, storm tracks and surface weather. Nat Geosci 8:433440. doi:10.1038/NGEO2424

Kim B-K, Son S-W, Min S-K, Jeong J-H, Kim S-J, Zhang X, Shim T, Yoon J-H (2014) Weakening of the stratospheric polar vortex by Arctic sea-ice loss. Nat Commun 5:4646. doi:10.1038/ ncomms5646

Knight JR, Folland CK, Scaife AA (2006) Climate impacts of the Atlantic multidecadal oscillation. Geophys Res Lett 33:L17706. doi:10.1029/2006GL026242

Kosatsky T (2005) The 2003 European heatwaves. Eur Commun Dis J 10:148

Krueger O, Schenk F, Feser F, Weisse R (2013) Inconsistencies between long-term trends in storminess derived from the 20CR reanalysis and observations. J Clim 26:868-874. doi:10.1175/ JCLI-D-12-00309.1 
Liu J, Chen Z, Francis J, Song M, Mote T, Hu Y (2016) Has Arctic sea ice loss contributed to increased surface melting of the Greenland ice sheet? J Clim. doi:10.1175/JCLI-D-15-0391.1

Lockwood M (2012) Solar influences on global and regional climates. Surv Geophys 33:503-534. doi:10.1007/s10712-012-9181-3

MacLachlan C, Arribas A, Peterson KA, Maidens A, Fereday D, Scaife AA, Gordon M, Vellinga M, Williams A, Comer RE, Camp J, Xavier P, Madec G (2014) Global seasonal forecast system version 5 (GloSea5): a high-resolution seasonal forecast system. Q J R Meteorol Soc 141:1072-1084. doi:10.1002/qj.2396

Matsumura S, Zhang X, Yamazaki K (2014) Summer Arctic atmospheric circulation response to spring Eurasian snow cover and its possible linkage to accelerated sea ice decrease. J Clim 27:65516558. doi:10.1175/JCLI-D-13-00549.1

Moore GWK (2012) Decadal variability and a recent amplification of the summer Beaufort Sea High. Geophys Res Lett 39:L10807. doi:10.1029/2012GL051570

Mysak LA, Venegas SA (1998) Decadal climate oscillations in the Arctic: a new feedback loop for atmosphere-ice-ocean interactions. Geophys Res Lett 25(19):3607-3610

Nakanowatari T, Sato K, Inoue J (2014) Predictability of the Barents Sea ice in the early winter: remote effects of oceanic and atmospheric thermal conditions from the North Atlantic. J Clim 27:8884-8901. doi:10.1175/JCLI-D-14-00125.1

Ogi M, Wallace JM (2012) The role of summer surface wind anomalies in the summer Arctic sea ice extent in 2010 and 2011. Geophys Res Lett 39:L09704. doi:10.1029/2012GLO51330

Overland JE, Francis JA, Hanna E, Wang M (2012) The recent shift in early summer Arctic atmospheric circulation. Geophys Res Lett 39:L19804. doi:10.1029/2012GL053268

Petoukhov V, Rahmstorf S, Petri S, Schellhuber H-J (2013) Quasiresonant amplification of planetary waves and recent northern hemisphere weather extremes. Proc Natl Acad Sci USA 110(14):5336-5341. doi:10.1073/pnas. 1222000110

Rayner NA, Parker DE, Horton EB, Folland CK, Alexander LV, Rowell DP, Kent EC, Kaplan A (2003) Global analyses of sea surface temperature, sea ice, and night marine air temperature since the late nineteenth century. J Geophys Res Atmos 108(D14):4407. doi:10.1029/2002JD002670

Robinson DA, Estilow TW, NOAA CDR Program (2012) NOAA climate data record (CDR) of northern hemisphere $(\mathrm{NH})$ snowcover extent (SCE), v01r01. NOAA National Climatic Data Center. doi: 10.7289/V5N014G9. Accessed 13 Feb 2015

Scaife AA, Ineson S, Knight JR, Gray L, Kodera K, Smith DM (2013) A mechanism for lagged North Atlantic climate response to solar variability. Geophys Res Lett 40:434-439. doi:10.1002/ grl.50099

Screen J (2013) Influence of Arctic sea ice on European summer precipitation. Environ Res Lett 8:044015. doi:10.1088/1748-9326/8/4/044015

Screen JA, Simmonds I (2013) Exploring links between Arctic amplification and mid-latitude weather. Geophys Res Lett 40:959964. doi:10.1002/grl.50174

Strong C, Magnusdottir G (2011) Dependence of NAO variability on coupling with sea ice. Clim Dyn 36:1681-1689. doi:10.1007/ s00382-010-0752-z
Sutton RT, Dong B (2012) Atlantic Ocean influence on a shift in European climate in the 1990s. Nat Geosci 5:788-792. doi:10.1038/ ngeo1595

Thiéblemont R, Matthes K, Omrani N-E, Kodera K (2015) Solar forcing synchronizes decadal North Atlantic climate variability. Nat Commun 8:8268. doi:10.1038/ncomms9268

Toniazzo T, Scaife AA (2006) The influence of ENSO on winter North Atlantic climate. Geophys Res Let 33:L24704. doi:10.10 29/2006GL027881

Torrence C, Compo GP (1998) A practical guide to wavelet analysis. Bull Am Meteorol Soc 79(1):61-78

Vallis GK, Gerber EP (2008) Local and hemispheric dynamics of the North Atlantic Oscillation, annular patterns and the zonal index. Dyn Atmos Oceans 44:184-212. doi:10.1016/j. dynamoce.2007.04.003

Wang J, Ikeda M, Zhang S, Gerdes R (2005) Linking the northern hemisphere sea-ice reduction trend and the quasi-decadal arctic sea-ice oscillation. Clim Dyn 24:115-130. doi:10.1007/ s00382-004-0454-5

Wilks DS (2006) On "field significance" and the false discovery rate. J Appl Meteorol Clim 45:1181-1189

Wilks DS (2011) Statistical methods for the atmospheric sciences, 3rd edn. Academic Press, New York

Woollings T (2010) Dynamical influences on European climate: an uncertain future. Philos Trans R Soc A 368:3733-3756. doi:10.1098/rsta.2010.0040

Woollings T, Blackburn M (2012) The North Atlantic jet stream under climate change and its relation to the NAO and EA patterns. J Clim 25:886-902. doi:10.1175/JCLI-D-11-00087.1

Woollings T, Hannachi A, Hoskins B (2010) Variability of the North Atlantic eddy-driven jet stream. Q J R Meteorol Soc 136(856):868. doi:10.1002/qj.625

Wu Q, Zhang X (2010) Observed forcing-feedback processes between northern hemispheric atmospheric circulation and Arctic sea ice coverage. J Geophys Res Atmos 115:D14119. doi:10.1029/200 9JD013574

Wu B, Zhang R, D'Arrigo R, SU J (2013) On the relationship between winter sea ice and summer atmospheric circulation over Eurasia. J Clim 26:5523-5536. doi:10.1175/JCLI-D-12-00524.1

Wu Q, Zhang J, Zhang X, Tao W (2014) Interannual variability and long-term changes of atmospheric circulation over the Chukchi and Beaufort Seas. J Clim 27:4871-4889. doi:10.1175/ JCLI-D-13-00610.1

Yoo C, Lee S, Feldstein S (2012) Mechanisms of arctic surface air temperature change in response to the Madden-Julian Oscillation. J Climate 25:5777-5790. doi:10.1175/JCLI-D-11-00566.1

Zhang X, Sorteberg A, Zhang J, Gerdes R, Comiso JC (2008) Recent radical shifts of atmospheric circulations and rapid changes in Arctic climate system. Geophys Res Lett 35:L22701. doi:10.10 29/2008GL035607

Zhao P, Zhang X, Zhou X, Ikeda M, Yin Y (2004) The sea ice extent anomaly in the North Pacific and its impact on the East Asian summer monsoon rainfall. J Clim 17:3434-3447 